Effect of Enzyme Activity and Frozen Storage on Jalapeño Pepper Volatiles by Selected Ion Flow Tube - Mass Spectrometry

\author{
Thesis
}

Presented in Partial Fulfillment of the Requirements for the Degree Master of Science in the Graduate School of The Ohio State University

\title{
By
}

Carolina Azcarate, B.S.

Graduate Program in Food Science and Technology

The Ohio State University

2010

Thesis Committee:

Sheryl A. Barringer, Advisor

John H. Litchfield

Luis E. Rodriguez-Saona 
Copyright by

Carolina Azcarate

2010 


\begin{abstract}
Samples of unblanched (fresh), stannous chloride-treated or blanched jalapeño peppers were measured for real-time generation of lipoxygenase-derived volatiles during 10 min after tissue disruption. Volatiles were also measured before and after 1.5, 2.5, 3, 6 and 9 mo of frozen storage at $-15^{\circ} \mathrm{C}$. The concentration of all lipoxygenase-derived compounds was significantly higher in unblanched jalapeño peppers compared to enzyme inhibited peppers. The maximum concentration of $(Z)$-3-hexenal, $(E)$-2-hexenal, and hexanal was detected at about 1.2, 1.5, and 1.5 min after tissue disruption, respectively. A decrease in (Z)-3-hexenal and an increase in dimethyl sulfide and methylbutanal occurred in blanched peppers due to heat. Frozen storage resulted in no major changes in the LOXderived volatiles of whole and pureed blanched peppers after 9 mo. However, in whole unblanched peppers a gradual decrease of $(Z)$-3-hexenal, $(E)$-2-hexenal, hexanal, hexenol and hexanol was observed over time; whereas in pureed unblanched peppers these compounds increased, reached maximum concentration and then decreased. Similarly, the minor LOX-volatiles 2-pentenal, 1-penten-3-one, $(E)$-2-heptenal, $(E)$-2-octenal, and (E)-2-nonenal showed an initial increase followed by a decline in both whole and pureed unblanched peppers. Tissue disruption increased generation and degradation rates during frozen storage. The compounds (E,Z)-2,6-nonadienal, n-propyl aldehyde, 2-isobutyl-3-
\end{abstract}


methoxypyrazine, and a mixture of terpenes decreased in unblanched and blanched frozen samples; while nonanal and methylbutanal increased only in unblanched samples.

\section{PRACTICAL APPLICATIONS}

Data obtained in this study contributes to the understanding of the dynamics of LOX-derived volatiles formation upon tissue disruption of jalapeño pepper. Additionally, it contributes to generate knowledge on the effect of processing techniques namely blanching and frozen storage on the volatile profile of these peppers. This knowledge has application in the manufacturing, product development and quality control areas of the food industry as useful information to help in the designing and monitoring of processes aimed to obtain products with specific aroma characteristics. For instance, maximum levels of "fresh" and "green" aroma compounds are achieved rapidly during the first few minutes after pepper tissue is broken. The inhibition of enzyme activity right after this point may help to maximize concentration of these aroma notes in the product. Frozen storage produces enzymatic and chemical changes in the volatile profile of unblanched peppers. The aroma profile of blanched peppers is more stable under frozen conditions, with a lower total volatile concentration. 


\section{DEDICATION}

To my parents Rosa Maria and Francisco 


\section{ACKNOWLEDGEMENTS}

I would like to thank my advisor Dr. Sheryl A. Barringer for her dedicated guidance, support, and encouragement throughout my M.S. studies. I also want to thank

Dr. John Litchfield and Dr. Luis Rodriguez-Saona for serving as my committee members, and for their genuine dedication to education.

My sincerest gratitude to Daniel for his continuous advice and encouragement, and for opening my eyes to a whole new world of invaluable experiences and growing opportunities.

I would like to extend my gratitude to my lab mates and student colleagues; thank you for your advice and support. Special thanks to my friends Fer, Alejandra, Huseyin, Gulsah, and Yelena for all the good moments that made this experience truly enjoyable.

Finally, I am grateful to the Fulbright Commission for giving me the opportunity of studying my M.S. degree at The Ohio State University. 


\section{VITA}

\begin{tabular}{|c|c|}
\hline \multirow[t]{2}{*}{$1998-2002 \ldots$} & B.S. Food Industry Engineering. La Molina \\
\hline & National Agricultural University. Peru. \\
\hline \multirow[t]{2}{*}{$2003-2004 \ldots$} & Quality Control Assistant. Alimentum \\
\hline & S.A.C. Peru. \\
\hline $2004-2008 \ldots$ & Food Product Developer. Alicorp S.A. Peru. \\
\hline 2008 - Present.. & Graduate Research Associate, Department \\
\hline
\end{tabular}

\section{FIELDS OF STUDY}

Major Field: Food Science and Technology 


\section{TABLE OF CONTENTS}

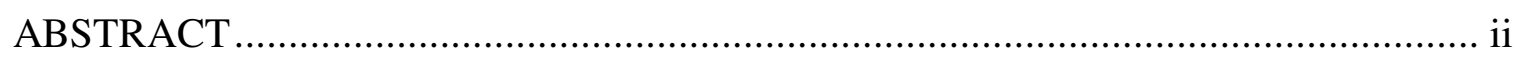

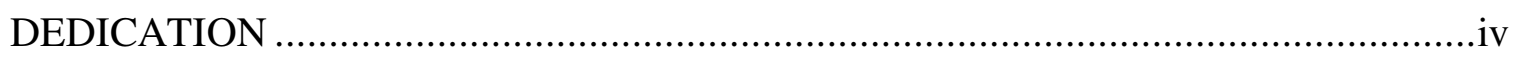

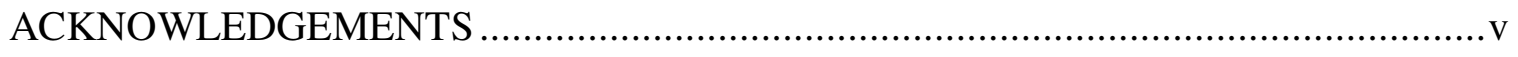

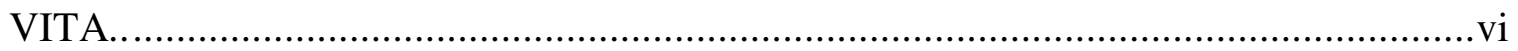

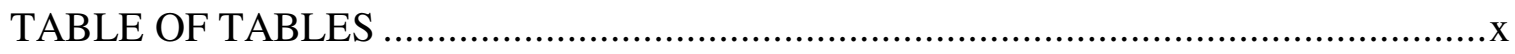

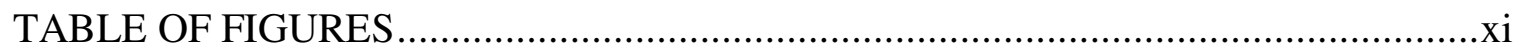

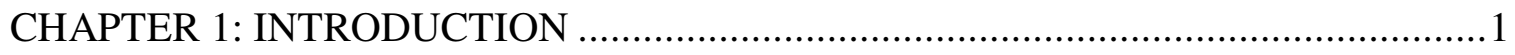

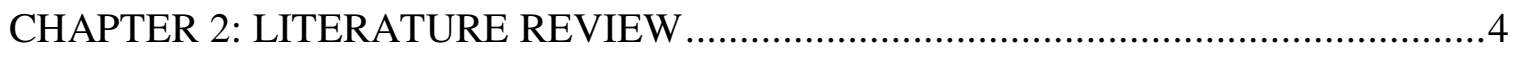

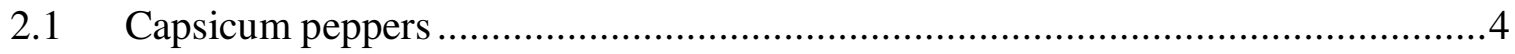

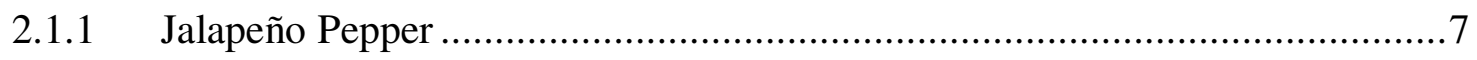

2.1.2 Importance and Uses of Capsicum fruits .............................................. 8

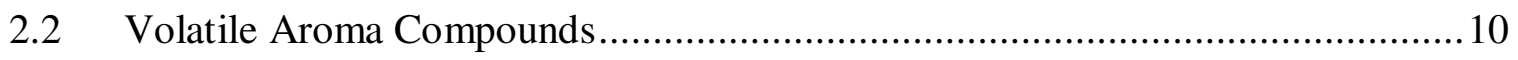

2.2.1 Volatile Aroma Compounds in Capsicum fruits...............................................11

2.2.2 Volatile generation by the Lipoxygenase pathway .........................................16

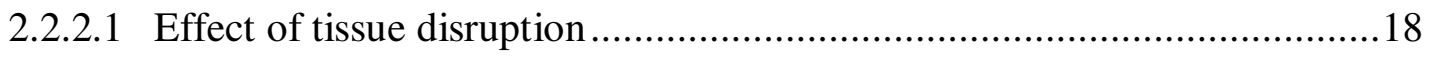

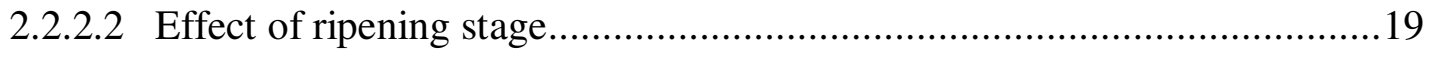

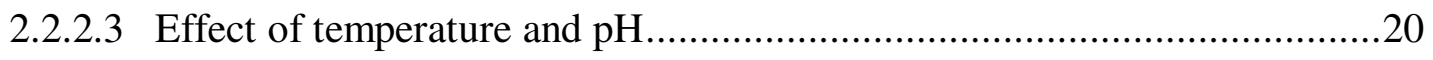
vii 
2.2.2.4 Enzyme inhibitors ................................................................. 21

2.2.3 Effect of Processing on volatile aroma compounds.....................................22

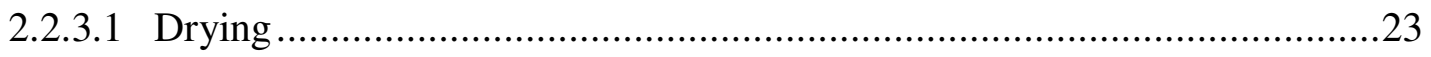

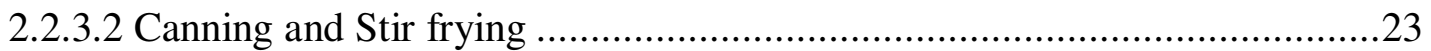

2.2.3.3 Blanching .......................................................................... 24

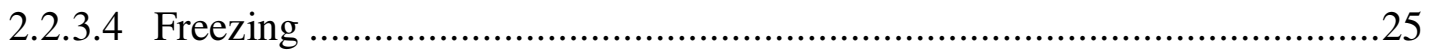

2.3 Analysis of Volatile Aroma Compounds ................................................26

2.3.1 Isolation and Separation techniques....................................................2

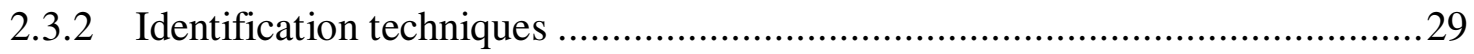

2.3.3 Selected Ion Flow Tube - Mass Spectrometry .........................................31

CHAPTER 3: MATERIALS AND METHODS..................................................... 34

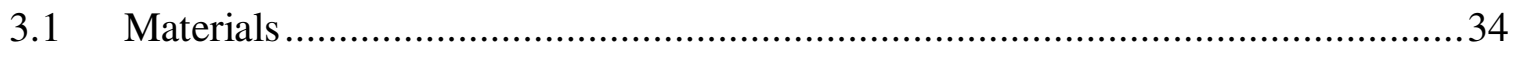

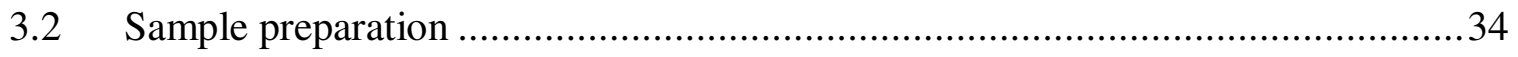

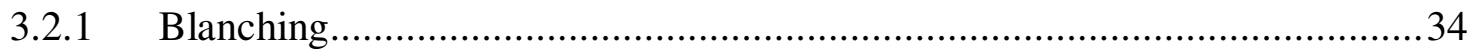

3.2.2 Effect of enzyme activity on volatile formation ................................... 35

3.2.3 Effect of frozen storage on volatile profile ...................................... 35

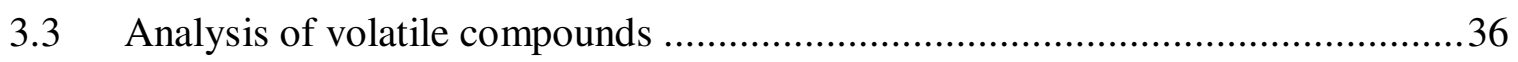

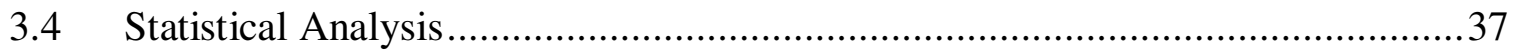

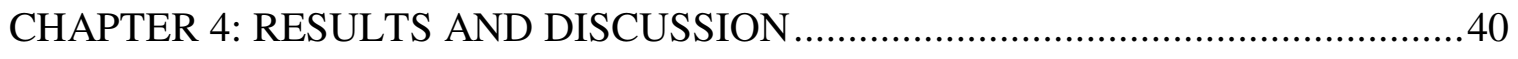

4.1 Effect of lipoxygenase pathway on volatile formation ................................ 40

4.1.1 Real-time monitoring of LOX-derived volatiles generation ........................43

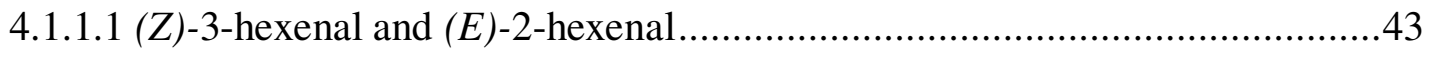


4.1.1.2 Hexanal

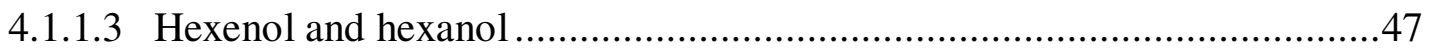

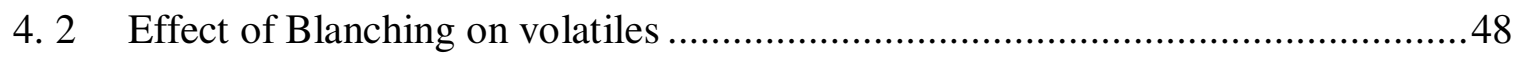

4.3 Effect of frozen storage on LOX-derived volatiles .....................................51

4.3.1 Blanched peppers ....................................................................... 51

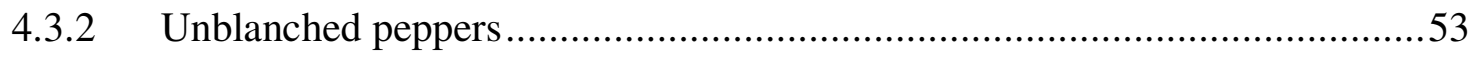

4.3.2.1 LOX-derived Major volatiles......................................................53

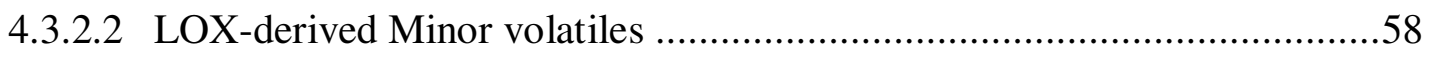

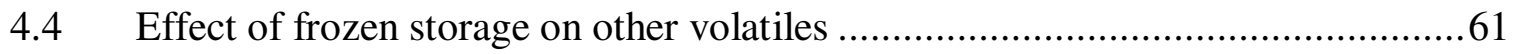

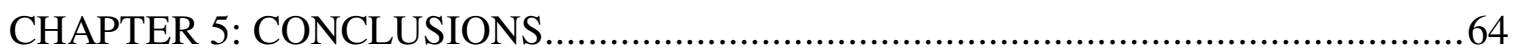

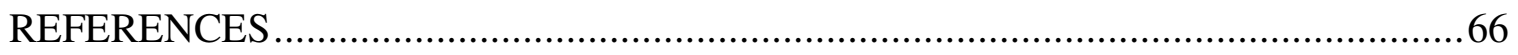




\section{TABLE OF TABLES}

Table 2.1: Domesticated Capsicum species ...............................................................6

Table 2.2: Major volatile compounds found in capsicum fruits .....................................15

Table 3.1: Kinetics Parameters for SIFT-MS Analysis of Selected Volatile Compounds

Table 4.1: Effect of frozen storage on some volatiles in unblanched and blanched jalapeño peppers. Values with different letters for the same compound within a group,

unblanched or blanched, are significantly different. 


\section{TABLE OF FIGURES}

Figure 2.1: Major components of Capsicum fruit ............................................

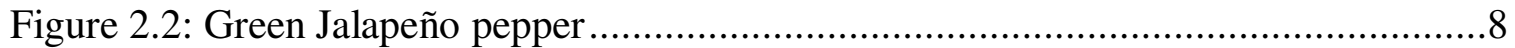

Figure 2.3: Volatile compounds generated by the lipoxygenase pathway proposed for bell

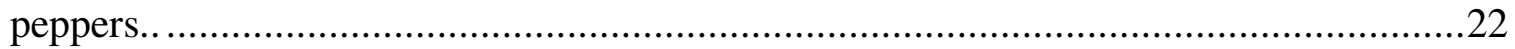

Figure 2.4: $\quad$ SIFT instrument, model Voice 100, Syft Technologies Inc........................33

Figure 2.5: Graphic representation of main internal processes of SIFT-MS instrument..33 Figure 4.1: Effect of enzyme activity on the concentration of LOX-derived volatiles in

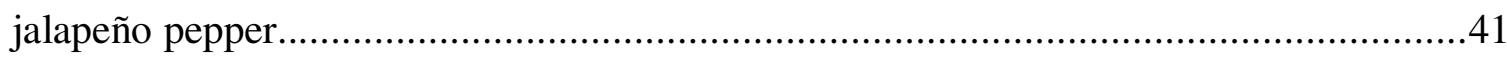

Figure 4.2: Real-time generation of LOX-derived volatiles in unblanched, SnCl2-treated,

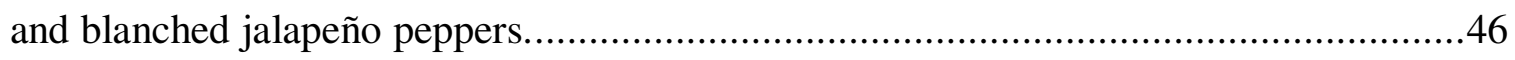

Figure 4.3: Effect of blanching on methylbutanal and dimethyl sulfide. .......................50

Figure 4.4: Effect of frozen storage on LOX volatiles of whole and pureed blanched

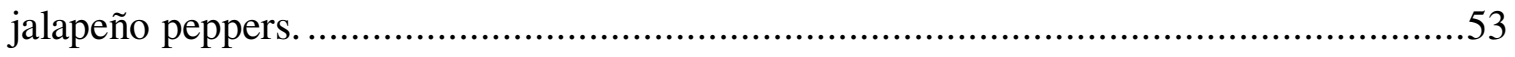

Figure 4.5: Effect of frozen storage on major LOX aldehydes and their corresponding alcohols in whole unblanched jalapeño peppers from 0 to 3 mo. 
Figure 4.6: Effect of frozen storage on major LOX aldehydes and their corresponding alcohols in whole unblanched jalapeño peppers at 6 and 9 mo.

Figure 4.7: Effect of frozen storage on major LOX aldehydes and their corresponding alcohols in pureed unblanched jalapeño peppers. ..........................................57

Figure 4.8: Effect of frozen storage on minor LOX volatiles of whole unblanched

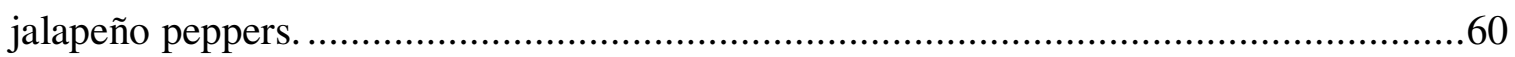

Figure 4.9: Effect of frozen storage on minor LOX volatiles of pureed unblanched

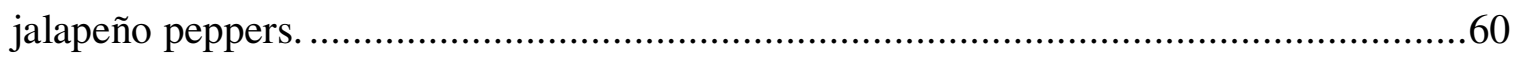




\section{CHAPTER 1}

\section{INTRODUCTION}

Jalapeño (Capsicum annuum L.), a capsicum pepper originating in Mexico, is the most popular chili cultivar in North America (Galicia-Cabrera 2006). It is greatly appreciated for its pleasant aroma and mild pungency.

Few studies have been conducted regarding the volatile compounds present in jalapeño pepper or the effect of processing on its flavor. Some compounds identified in this pepper are 2-isobutyl-3-methoxypyrazine (Huffman and others 1978; Chitwood and others 1983), (Z)-3-hexenol and linalool (Keller and others 1981; Chitwood and others 1983).

More than 125 volatile compounds have been identified in other Capsicum peppers (Pino and others 2007). Some of the most important compounds are the group of six-carbon (C6) aldehydes and alcohols generated by the lipoxygenase pathway. This oxidative pathway initiated by the lipoxygenase enzyme is responsible for the formation of these aldehydes and alcohols from C18 polyunsaturated fatty acids in various fruits and vegetables upon tissue disruption (Wu and Liou 1986; Buttery and others 1987). The C6 volatile compounds hexanal, (Z)-3-hexenal, (E)-2-hexenal, hexanol, (Z)-3-hexenol, 
and $(E)$-2-hexenol are associated with the fresh and green notes of Capsicum peppers (Luning and others 1994).

Other major volatiles found in Capsicum peppers are the terpenes limonene, linalool, $(E)$ - $\beta$-ocimene, and $\delta$-3-carene; the compound 2-methoxy-3-isobutylpyrazine; the aldehydes $(E, Z)-2,6$-nonadienal and $(E, E)$-2,4-decadienal; the esters methyl salicylate and ethyl acetate; and the ketones 1-penten-3-one and 2,3-butanedione (Buttery and others 1969; Chitwood and others 1983; Luning and others 1994).

Processing techniques generally result in some degree of alteration of the sensory characteristics of fresh capsicum peppers, especially its flavor. Freezing, for instance, increased the content of terpenes, pyrazines, and phenols of Padrón-type peppers; whereas homogenization increased the content of aldehydes, esters, pyrazines, and phenols; and produced a loss of ethers, pyrroles, and sulfurous compounds (OruñaConcha and others 1998). Dried blanched green peppers resulted in reduced fresh green pepper aroma, associated with the compound 2-isobutyl-3-methoxypyrazine, when compared to unblanched dried peppers (Kuzniar and others 1983).

Selected Ion Flow Tube - Mass Spectrometry (SIFT-MS) is a relatively modern technique used initially for the analysis of trace gases in air and for clinical breath analysis that has expanded its application to the food industry for the analysis of aroma compounds. The main advantage of this technique is that it requires minimal sample preparation, it is fast, and allows for a real-time monitoring of selected volatile compounds providing differentiation of some isomers. 
The objective of this study was to evaluate the effect of enzymatic activity, particularly the lipoxygenase pathway, on the generation of aroma compounds; as well as the effect of frozen storage on the volatile profile of whole and pureed jalapeño peppers using SIFT-MS. 


\section{CHAPTER 2}

\section{LITERATURE REVIEW}

\subsection{Capsicum peppers}

Capsicum peppers are pods that have been used as spices since ancient times. They are originally from Central and South America, and then they were introduced to Europe as a result of the colonization expeditions during Christopher Columbus's times. Subsequently, capsicum peppers spread to Asia and Africa through trading routes of the Spanish and Portuguese. Today capsicum peppers are distributed and consumed worldwide. There is evidence of their use in the Mexican Indian diet as early as 7000 B.C. and of their being grown by Indians between 5200 B.C. and 3400 B.C. These records position capsicums among the oldest cultivated plants in America (Govindarajan 1985; Bosland and Votava 2000).

Capsicum peppers belong to the genus Capsicum which is a member of the family Solanaceae. This family also comprises the genus Solanum which is closely related to Capsicum and includes several economically important plants such as tomato, potato, 
eggplant, and tobacco (Govindarajan 1985). Taxonomists have identified 5 domesticated (Table 2.1) and at least 25 wild species of capsicums (Bosland and Votava 2000).

The fruits, botanically classified as berries, vary in shape, size, color, flavor, and pungency. Color ranges from green to purple to yellow to red. They are commonly called peppers, and they can be "sweet" such as bell peppers or "hot" such as chili peppers. The main components of the fruit are pedicel, placenta, seeds, and pericarp (Rajput and Parulekar 1998) (Figure 2.1). 


\begin{tabular}{|c|c|c|c|}
\hline Species & Characteristics & Distribution & Cultivar examples \\
\hline Capsicum аппиит & $\begin{array}{l}\text { The most widely grown. Presence of } \\
\text { calyx teeth. White large corolla. } \\
\text { Yellow, smooth seeds. Fruits are } \\
\text { varied in size, shape and color. }\end{array}$ & $\begin{array}{l}\text { Colombia to southern } \\
\text { United States, } \\
\text { throughout Latin } \\
\text { America, Asia }\end{array}$ & $\begin{array}{l}\text { Bell pepper, Cayenne, } \\
\text { Jalapeño, Paprika, } \\
\text { Poblano, Pimiento, } \\
\text { Serrano. }\end{array}$ \\
\hline Capsicum baccatum & $\begin{array}{l}\text { Presence of short calyx teeth. Cream } \\
\text { to white corolla with yellow to green } \\
\text { spots. Yellow anthers. Fruits are } \\
\text { pendant, diverse in color, and } \\
\text { usually elongated. }\end{array}$ & $\begin{array}{l}\text { Argentina, Bolivia, } \\
\text { Brazil, Colombia, } \\
\text { Ecuador, Peru, } \\
\text { Paraguay, etc }\end{array}$ & $\begin{array}{l}\text { Ají Amarillo, Ají } \\
\text { Colorado, Ají Limo. }\end{array}$ \\
\hline Capsicum frutescens & $\begin{array}{l}\text { Not widely cultivated. Absent teeth } \\
\text { calyx. Greenish white corolla. } \\
\text { Purple anthers. Fruits are usually } \\
\text { small, pointy, and erect. }\end{array}$ & $\begin{array}{l}\text { Colombia, Costa Rica, } \\
\text { Guatemala, Mexico, } \\
\text { Puerto Rico, } \\
\text { Venezuela }\end{array}$ & $\begin{array}{l}\text { Tabasco, Malagueta, } \\
\text { Birdseye. }\end{array}$ \\
\hline Capsicum chinense & $\begin{array}{l}\text { Absence of calyx teeth. White } \\
\text { corolla. Fruits are varied, firm- } \\
\text { fleshed, and usually pendant. } \\
\text { Distinctive fruity aroma. Includes } \\
\text { many of the hottest cultivars. }\end{array}$ & $\begin{array}{l}\text { Bolivia to Brazil, } \\
\text { Belize, Costa Rica, } \\
\text { Mexico, Nicaragua, } \\
\text { West Indies }\end{array}$ & $\begin{array}{l}\text { Habanero, Scotch } \\
\text { Bonnet, Red Savina. }\end{array}$ \\
\hline Capsicum pubescens & $\begin{array}{l}\text { Presence of small calyx teeth. Purple } \\
\text { corolla. Purple and white anthers. } \\
\text { Black rugose seeds. Fruits have } \\
\text { usually a pear or apple shaped, and a } \\
\text { distinctive neck. }\end{array}$ & $\begin{array}{l}\text { Bolivia to Colombia, } \\
\text { Costa Rica, } \\
\text { Guatemala, Honduras, } \\
\text { Mexico }\end{array}$ & Rocoto, Manzano \\
\hline
\end{tabular}

Table 2.1: Domesticated Capsicum species Sources: Rajput and Parulekar (1998) and Eshbaugh (1975). 


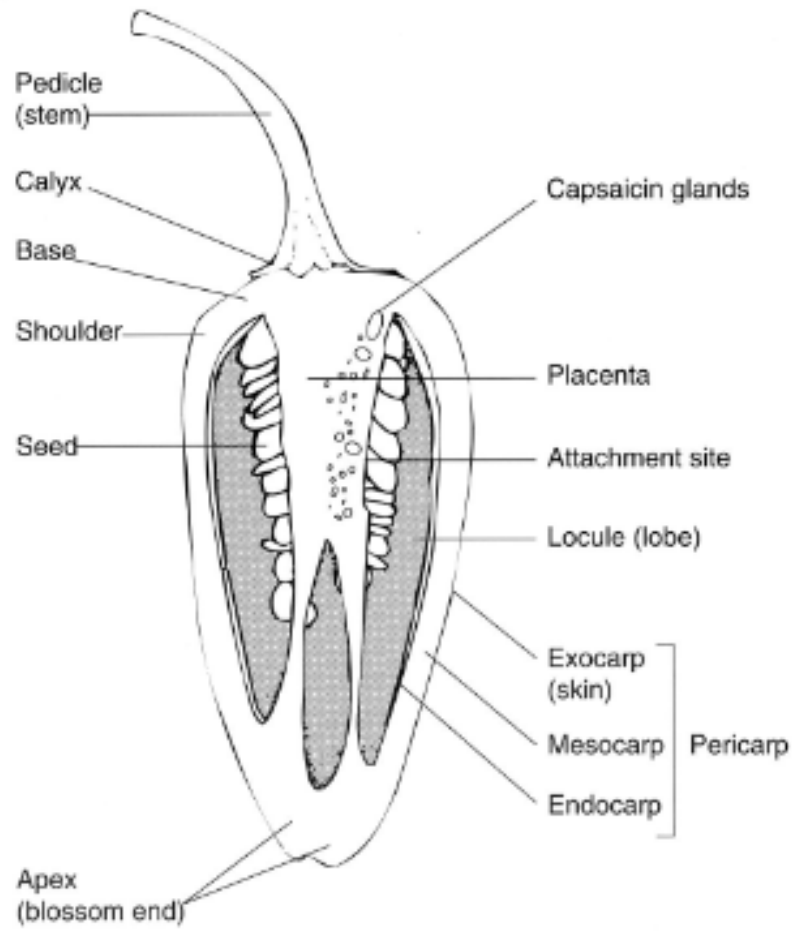

Figure 2.1: Major components of Capsicum fruit Source: Rajput and Parulekar (1998)

\subsubsection{Jalapeño Pepper}

Jalapeño pepper, traditionally cultivated in the city of Jalapa, situated in the Mexican state of Veracruz, is one of the most important chili cultivars in Mexico and the most popular in North America (Galicia-Cabrera 2006). Belonging to the species Capsicum annuum, this chili pepper is medium to large in size, elongated in shape, fleshy, and pungent (Figure 2.2).

The pepper can be consumed at the unripe stage when it is intense green in color or at the ripe stage when it is red. Usually, when harvested ripe these peppers are smokedried to give the also popular product "Chipotle" (Galicia-Cabrera 2006). 
Jalapeño pepper is used in a variety of Mexican traditional dishes where it is appreciated for its characteristic flavor and moderate hotness. About $20 \%$ of production is consumed fresh, while the rest is processed by freezing, canning, dehydration, and pickling (Galicia-Cabrera 2006).

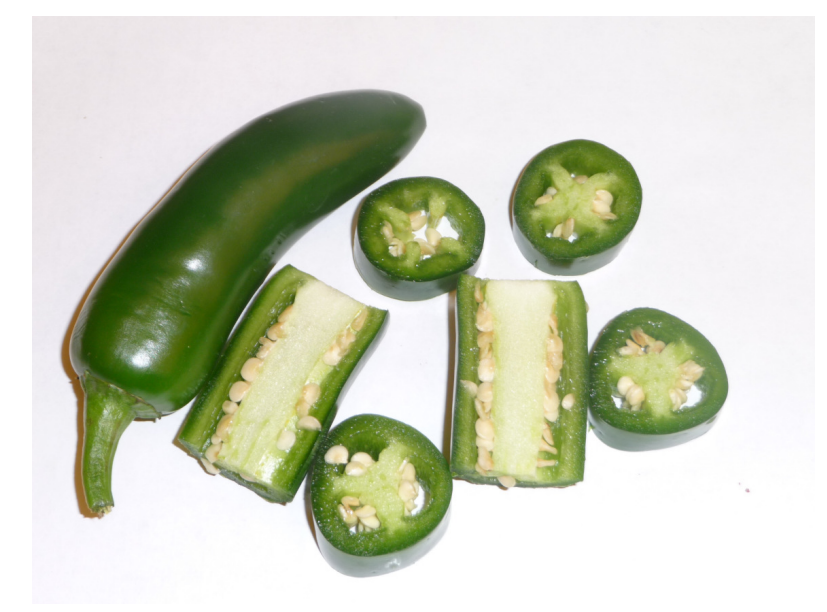

Figure 2.2: Green Jalapeño pepper

\subsubsection{Importance and Uses of Capsicum fruits}

Since times dating from before the arrival of the European conquers, native Indians from South and Central America have been cultivating capsicum fruits not only for use as a food condiment but also for medicine and even for warfare purposes. These fruits were used as a cure for cramps and diarrhea; as well as for fighting Spanish invaders by producing an extremely irritating smoke when burned (Govindarajan 1985). 
After the colonization process, the cultivation and consumption of capsicum fruits has spread all over the world. Nowadays, capsicum fruits are one of the major commodities in the world offering a wide variety of applications.

In the medicine field, capsicums are used as a natural remedy for pain relief in cases of arthritis, mastectomy post-operative pain, and phantom limb pain (Bosland and Votava 2000). The effect is related to capsaicinoids, the compounds responsible for the pungency of chili peppers. In the cosmetic field, they are used as colorings due to their carotenoid content; and in food manufacturing they are appreciated for imparting flavoring and coloring to many types of foods such as sausages, sauces and soups (Bosland and Votava 2000). As for their nutritional value, peppers are a good source of vitamins. They are rich in pro-vitamin A, vitamin E, and especially in vitamin C (Bosland and Votava 2000).

Regarding their culinary use, capsicum peppers have become a distinctive feature in many ethnic cuisines such as Mexican, Peruvian, Indian, and Chinese. Capsicum peppers, consumed as vegetables or as spices, are greatly valued for their sensory attributes: flavor, aroma, and characteristic "hot" sensation when eaten. Among their attributes, one of the most important is the aroma, which is pleasant and enhances the flavor and acceptability of other generally bland foods (Govindarajan 1985; Buttery and others 1969).

Currently, there are numerous options for the processing of capsicum fruits. Thus, peppers are used for the production of dehydrated spices, such as paprika, pickled 
peppers, sauces, salsa, sliced or diced frozen peppers for use in pizzas or to be eaten raw in salads (Castro and others 2008).

As a result of their high versatility and important role in food and many other areas, the interest and consumption of capsicum peppers is rapidly growing around the world. This interest is reflected by an increasing amount of research, seed development, and search for new applications that will offer the consumer a wider range of new flavors and novel products (Bosland and Votava 2000).

\subsection{Volatile Aroma Compounds}

Since the origins of humankind odor and taste have been sensorial attributes used instinctively for helping in the selection of foods. Later, preparation techniques such as cooking, baking and roasting were developed as they generate desirable flavors that increase the palatability of foods (Maarse 1991).

Volatile compounds are chemical compounds that vaporize at room temperature. These volatilized compounds travel through the air and reach the olfactory receptors located in the upper part of our nose, generating a chemical response which is perceived as an odor or smell. Volatile compounds, also called aroma compounds, can be found in food, perfume, wine, spices and essential oils. In the case of fruit and vegetables, they are formed biochemically in different stages; for example, some compounds are formed during the growth of the fruit, others during the ripening process and others after harvesting. In wines, most form as byproducts of fermentation. 
Flavor is a complex sensation determined mainly by the senses of taste and smell in the mouth and nose (Bosland and Votava 2000). Aroma concentrates are very complex, containing hundreds of different compounds in variable concentrations. Therefore, flavor chemists have been constantly required to develop innovative and suitable techniques to isolate and identify these individual compounds (Maarse 1991).

Although few advances have been done in terms of perception mechanisms and the sensorial contribution of each volatile compound to the overall aroma of foods, researchers have developed a useful concept called the "odor unit". The Odor unit is the ratio of the concentration of the compound divided by its threshold, and gives an idea of the contribution of each compound to the total aroma (Buttery and others 1987).

\subsubsection{Volatile Aroma Compounds in Capsicum fruits}

Capsicum fruits possess numerous volatile compounds, which are responsible for their characteristic aroma. Several studies have investigated the volatile compounds in fresh and processed Capsicum fruits, indentifying more than 125 compounds (Pino and others 2007). These compounds belong to several chemical classes such as: phenols, aldehydes, acids, ketones, alcohols, ethers, nitrogen compounds, aromatic hydrocarbons, alkanes, esters, and lactones (Mateo and others 1997).

The aroma of capsicums results from the complex mixture of all of the individual volatile compounds present in the fruit. Each compound confers a distinctive odor which contributes to the characteristic overall aroma of the fruit. Buttery and others (1969) identified for the first time the compound 2-methoxy-3-isobutylpyrazine, which has been 
recognized to possess a strong odor similar to that of fresh green bell peppers. This compound has been found to be important not only to green bell pepper aroma, but also to the aroma of other varieties of peppers, including chili peppers. Huffman and others (1978) suggested that the characteristic flavor of fresh jalapeño pepper is attributed to the compound 2-isobutyl-3-methoxypyrazine, the same compound responsible for fresh bell pepper flavor. The compounds (Z)-3-hexenol, 4-methylpentanol, linalool, alpha-terpineol, beta-ionone, 4-methyl-1-pentyl-2-methyl-butyrate, and 4-methyl-1-pentyl-3-methylbutyrate were indentified in jalapeño peppers (Keller and others 1981).

Major components found in bell peppers are the terpenoids limonene, linalool, and trans- $\beta$-ocimene, as well as methyl salicylate, nona-(E,Z)-2,6-dienal, deca- $(E, E)-2,4-$ dienal, and (Z)-3-hexenol (Buttery and others 1969). $\delta$-3-Carene is the major monoterpene detected in a number of capsicum varieties (Oruña-Concha and others 1998). Some compounds have been related to a specific aroma, for instance: nona- $(E, Z)-$ 2,6-dienal as cucumber odor, deca-2,4-dienals as fried chicken, limonene as citrus, C9 ketones as sweet mushroom-like odor, and methyl salicylate as oil of wintergreen odor (Buttery and others 1969).

Naef and others (2008) identified 21 new sulfur containing compounds: 19 thiols and 2 dithiolanes, in red bell peppers. The sulfur-containing compounds detected correspond to heptane derivatives and nonane derivatives. These sulfur compounds contribute to the organoleptic profile of the bell peppers, even at very low concentrations. These compounds have various flavor notes including fruity, very green and vegetable- 
like, meaty, alliaceous and onion-like, sesame, peanut, coffee-like and roasted, and in some cases they have unpleasant, rubbery, rotten flavors (Naef and others 2008).

The aroma compounds of Tabasco pepper includes some alcohols such as 3methyl-1-pentanol, (Z)-3-hexenol, and hexanol; a few aromatic compounds such as benzaldehyde, and a large amount of esters which are thought to have a sweet-fruity aroma and probably make an important contribution to the aroma of Tabasco pepper (Haymon and Aurand 1971). Tabasco pepper aroma results from the combination of all of the components found, and not from just one characterizing aroma compound.

Researchers have investigated the volatile compounds of a number of capsicum fruits in the fresh state and also after different kinds of processing. According to the results, several differences among the studies are observed. These differences are suggested to be mainly due to the variety of the capsicum, the sample preparation and analysis chosen, and the changes in volatile compounds during processing (Mateo and others 1997).

The differences in volatile compounds between two varieties of Hungarian powdered paprika: "hot" and "sweet" were evaluated. "Hot" samples were significantly richer in number and amount of volatile compounds in comparison with "sweet" samples. Pungent samples contain much more terpene, sesquiterpene and terpene derivative constituents than sweet ones (Kocsis and others 2002). The composition of volatile compounds of ten Habanero chili pepper cultivars differed clearly among the different cultivars (Pino and others 2007). It appears evident from the studies that each cultivar of 
capsicum fruit has its particular blend of volatile compounds which confer a distinctive aroma.

Regarding sample preparation, Buttery and others (1969) obtained green pepper oil using two extraction methods: vacuum steam-distillation-continuous extraction, where the pepper puree was heated at $45^{\circ}$ to $50^{\circ} \mathrm{C}$, and atmospheric pressure steam-distillationcontinuous-extraction, where the pepper puree was heated at $100^{\circ} \mathrm{C}$. The oil obtained by the vacuum extraction method had an aroma similar to that of the original peppers whereas the oil obtained by the atmospheric pressure method had relative amounts of some components quite different from those found in the vacuum extracted oil. C9 ketones: non-1-en-4-one, non-(E)-2-en-4-one, and nona-(E,E)-2,5-dien-4-one, which were found in very small amounts in the vacuum extracted oil, become the major components in the atmospheric pressure extracted oil, and the major compounds in the vacuum extracted oil become relatively minor. Apparently, the C9 ketones are formed by heating and probably contribute to the cooked bell pepper aroma (Buttery and others 1969).

Although several studies have been conducted on the identification of volatile compounds in capsicum fruits, few authors have investigated the aroma contribution of each volatile compound identified (Zimmermann and Schieberle 2000; Kocsis and others 2002). Table 2.2 shows the most common volatile compounds found in capsicum fruits. 


\begin{tabular}{|c|c|c|}
\hline Chemical Group & Compounds & Flavor descriptor \\
\hline \multirow{7}{*}{ Aldehydes } & (Z)-3-hexenal & \multirow{3}{*}{ green, grassy, fresh aroma } \\
\hline & (E)-2-hexenal & \\
\hline & Hexanal & \\
\hline & (E, Z)-2,6-nonadienal & cucumber odor \\
\hline & $(\mathrm{E}, \mathrm{E})$-2,4-decadienal & fried chicken odor \\
\hline & $(\mathrm{E}, \mathrm{Z})$-2,4-decadienal & fried chicken odor \\
\hline & benzaldehyde & almond note \\
\hline \multirow{3}{*}{ Alcohols } & (Z)-3-hexenol & \multirow{3}{*}{ green, grassy, fresh aroma } \\
\hline & (E)-2-hexenol & \\
\hline & Hexanol & \\
\hline \multirow{5}{*}{ Esters } & Methyl salicylate & wintergreen-like odor \\
\hline & hexyl isopentanoate & fruity notes, apple \\
\hline & (Z)-3-hexenyl isopentanoate & fruity, sweet green, apple-like \\
\hline & hexyl pentanoate & fruity odor notes \\
\hline & ethyl acetate & sweet odor \\
\hline \multirow{4}{*}{ Terpenes } & $(E)$ - $\beta$-ocimene & rancid, sweaty odor \\
\hline & Limonene & citrus odor \\
\hline & Linalool & floral \\
\hline & 3-carene & $\begin{array}{l}\text { red bell pepper, } \\
\text { rubbery odor }\end{array}$ \\
\hline \multirow{8}{*}{ Ketones } & 1-penten-3-one & chemical/pungent, spicy odor \\
\hline & 2,3-butanedione & caramel odor \\
\hline & non-1-en-4-one & \multirow{5}{*}{$\begin{array}{c}\text { sweet mushroom-like odor, } \\
\text { contribute to the cooked bell pepper } \\
\text { aroma }\end{array}$} \\
\hline & non-(E)-2-en-4-one & \\
\hline & nona-(E,E)-2,5-dien-4-one & \\
\hline & 2-heptanone & \\
\hline & Hept-(E)-3-en-2-one & \\
\hline & $\beta$-ionone & violet-like, fruity, woody \\
\hline Bases & 2-methoxy-3-isobutylpyrazine & green bell pepper odor \\
\hline \multirow{2}{*}{ Furans } & furfural & almond note \\
\hline & 2-pentylfuran & \\
\hline
\end{tabular}

Table 2.2: Major volatile compounds found in capsicum fruits

Sources: Buttery and others (1969), Keller and others (1981), Chitwood and others (1983), Wu and Liou (1986), Luning and others (1994), Mateo and others (1997), Kim and others (2007), Pino and others (2007), Forero and others (2009). 


\subsubsection{Volatile generation by the Lipoxygenase pathway}

Lipoxygenases (LOX) are a group of enzymes present in the plant tissue that catalyzes the oxidation of polyunsaturated fatty acids resulting in the formation of fatty acid hydroperoxides (HPOs) (Chen et al. 2004). LOX enzymes can be divided into two groups: 9-LOX and 13-LOX, which form 9-HPO and 13-HPO respectively. These hydroperoxides are then cleaved by another type of enzyme, fatty acid hydroperoxide lyase (HPOL), which correspondingly can be 9-HPOL or 13-HPOL. The first will form two C9 fragments while the second will form a C6 and a C12 fragment from a C18 polyunsaturated fatty acid such as linoleic or linolenic acid (Chen and others 2004). The major polyunsaturated fatty acids in jalapeño peppers and tomatoes are linoleic and linolenic acid which are 95\% and 5\% respectively for jalapeño peppers, and 96\% and 4\% for tomatoes (USDA National Nutrient Database 2010).

Some of the roles attributed to LOX include plant growth and development, response to wounding, defense and insect attraction, and biosynthesis of regulatory molecules and volatile flavor compounds (Chen et al. 2004). Several isoforms of lipoxygenase have been identified, each one with individual subcellular locations, specificity, regulatory mechanisms, and functions. For instance, Chen and others (2004) suggested that TomloxC, one of the five LOX isoforms identified in tomatoes, is the major enzyme responsible for the formation of volatile C6 aldehyde and alcohol flavor compounds; while the other four isoforms were mainly related to defense response signaling and biosynthesis of regulatory and wounding response molecules. 
The lipoxygenase pathway involves several enzymes. It is initiated by the action of LOX enzyme on linoleic and linolenic acid to form HPOs. These HPOs will be subsequently cleaved by HPOL enzyme to generate aldehydes. Some of the aldehydes may be isomerized by the action of (Z)-3/(E)-2 isomerase (Z3/E2 ISO). Aldehydes are then converted into their respective alcohols by the action of alcohol dehydrogenase (ADH) (Luning and others 1995a).

The formation of characteristic flavor compounds from polyunsaturated fatty acids by the action of the lipoxygenase pathway has been reported for numerous food plant products including green and red fruits of Capsicum annuum varieties (Wu and Liou 1986; Buttery and others 1987; Luning and others 1994, 1995a). Hexanal is formed from the 13-HPO of linoleic acid, while (E)-2-nonenal and 2-pentylfuran are generated from its 9-HPO. (E)-2-Octenal and (E)-2-heptenal derive from the 10- and 12-HPO of linoleic acid respectively, which are formed by a rearrangement of its 9- and 13-HPO. Hexanol is formed from hexanal by the action of ADH. (Z)-3-Hexenal is produced from the 13-HPO of linolenic acid. (E)-2-Pentenal and 1-penten-3-one are also generated from the 13-HPO of linolenic acid through an alternative pathway involving unknown enzymes. (Z)-3-Hexenal is converted to (E)-2-hexenal by Z3/E2 ISO; these aldehydes are then reduced to their respective alcohols $(Z)-3-H e x e n o l$ and $(E)$-2-hexenol by ADH (Luning and others 1995a; Xu and Barringer 2009). The lipoxygenase pathway proposed for Luning and others (1995a) for the formation of volatile compounds in bell peppers is shown in Figure 2.3. 
Volatile C6 aldehyde and alcohol compounds such as hexanal, (Z)-3-hexenal, (E)2-hexenal, and (Z)-3-hexenol, which are specifically generated from 13-HPO, are known to be key flavor compounds responsible for the "fresh" and "green" notes of tomato (Chen and others 2004) and bell pepper aroma (Luning and others 1994).

\subsubsection{Effect of tissue disruption}

Hexanal, (E)-2-hexenal, hexanol, (Z)-3-hexenol, and (E)-2-hexenol are formed when bell peppers tissue is disrupted (Wu and Liou 1986). Tissue disruption allows for an increased interaction between enzymes and their substrates to form these aldehydes and alcohols.

Blended bell peppers had higher concentrations of volatile compounds than sliced bell peppers. Tissue disruption favored the formation of several odor-active compounds such as hexanal, (Z)-3-hexenal, (E)-2-hexenal, hexanol, (Z)-3-hexenol, 2-ethylfuran, and (E)-2-hexenol, due to the activity of oxidative and hydroperoxide-cleavage enzyme systems (Luning and others 1994). Likewise, Buttery and others (1987) determined that the total concentration of volatiles in diced or sliced tomatoes was lower than blended tomatoes, but the proportion of the volatiles was similar.

The generation of these volatile compounds occurs rapidly after tissue disruption. Maximum concentration of (Z)-3-hexenal was reached at 3 min after tissue disruption of tomatoes (Buttery and others 1987). In grape tomatoes, maximum levels of (Z)-3hexenal, $(E)$-2-hexenal, hexanal, and hexanol were reached after 3.3, 3.7, 4.7, and 3.7 min after blending, respectively (Xu and Barringer 2009). 
The concentration of LOX aldehydes and alcohols may vary significantly over time as they are being continuously transformed by enzymes. In grape tomatoes, the ratio of $(Z)$-3-hexenal to $(E)$-2-hexenal was 1.3:1 during the first 10 min after blending. In bell peppers, this ratio was 1:34 (Wu and Liou 1986).

The ratio of unsaturated to saturated C6 aldehydes and alcohols was 3:1 in bell peppers (Wu and Liou 1986). Luning and others (1995a) found a ratio of 2:1 and 5:1 in green and red bell peppers, respectively. Xu and Barringer (2009) found a ratio of 2.5:1 in grape tomatoes.

\subsubsection{Effect of ripening stage}

The composition of volatile compounds of bell peppers differ clearly between the maturation stages (Luning and others 1994, 1995a). In general, the majority of volatile compounds, of which several had green-related odor notes, decreased or disappeared during maturation, and only a few compounds increased upon ripening. Similarly the activity of LOX in bell peppers decreases significantly (more than 50\%) at the turning and red stages of maturation compared to the immature or mature green stages. Some compounds such as $(Z)$-3-hexenal and $(Z)$-3-hexenol decrease concentration from the green stage to turning or red stage as occurs with LOX activity. While other volatiles such as $(E)$-2-hexenal and $(E)$-2-hexenol significantly increase from the green to the turning stage. The ratio of $(Z)$-3-hexenal to $(E)$-2-hexenal was 1.2:1 and 1:28.5 in green and red bell peppers, respectively. An increase in $(Z)-3 /(E)-2$ isomerase activity during ripening was therefore suggested (Luning and others 1995a). 


\subsubsection{Effect of temperature and $\mathrm{pH}$}

No major difference was found between the concentration of volatiles in vineripened tomatoes and in room-temperature-ripened (for 7 days) supermarket tomatoes. However, hexanal and $(Z)-3$-hexenal were found to be 10 times lower when analyzed in refrigerated samples $\left(2^{\circ} \mathrm{C}\right)$ while still cold and 3 times lower in refrigerated samples $\left(2^{\circ} \mathrm{C}\right)$ allowed to warm to room temperature compared to vine-ripened tomatoes (Buttery and others 1987). The low concentration of volatiles in cold samples was expected since enzymatic activity is dependent on temperature. Nevertheless, the partial enzyme inactivation in refrigerated storage samples allowed to warm was not as simple to explain; it may be the result of some type of normal tomato metabolism (Buttery and others 1987).

The concentration of hexanal in the head space of blended grape tomatoes decreases at $37^{\circ} \mathrm{C}$ compared to $23^{\circ} \mathrm{C}$ (Xu and Barringer 2009). This may be explained by a decrease in enzyme activity at a temperature higher than the optimum range for tomato LOX on linoleic acid which is $20-30^{\circ} \mathrm{C}$. Another reason may be a reduced availability of the hexanal 13-HPO precursor due to the dominance of alternative pathways for linoleic acid at $37^{\circ} \mathrm{C}(\mathrm{Xu}$ and Barringer 2009).

Enzymatic activity is also affected by the $\mathrm{pH}$ of the medium. For LOX isolated from bell pepper, an optimum activity at $\mathrm{pH} 6$ for $\mathrm{cv}$. Mazurka and $\mathrm{pH} 6.5$ for $\mathrm{cv}$. Bola and cv. Agridulce has been reported (Minguez-Mosquera and others 1993; Luning and others 1995a). 


\subsubsection{Enzyme inhibitors}

Some of these enzymatically generated compounds are further degraded by other enzymes when broken tissue is held too long or during isolation by conventional methods (Buttery and others 1987). After the action of LOX, the primary compounds formed can be modified by others enzymes such as isomerases and alcohol dehydrogenases resulting in different volatile compounds (Luning and others 1995a). Therefore, to obtain a quantitative analysis of the generation of these important fresh compounds, researchers needed to inactivate the enzyme systems after their initial formation (Buttery and others 1987).

Different chemicals have been used for enzyme inactivation. Buttery and others (1987) used a saturated solution of $\mathrm{CaCl}_{2}$ to inactivate lipoxygenase in tomatoes. High concentrations of $\mathrm{NaCl}$ and other salts are used to inactivate enzyme systems; however, bivalent ions such as $\mathrm{Ca}^{2+}$ and $\mathrm{Mg}^{2+}$ are more effective in precipitating enzyme systems. Wu and Liou (1986) confirmed the enzyme-inhibition activity of stannous chloride in bell peppers. Finally, Luning and others (1995a) used n-propyl gallate and 5,8,11,14eicosatetraynoic acid (ETYA) solutions as LOX activity inhibitors. 


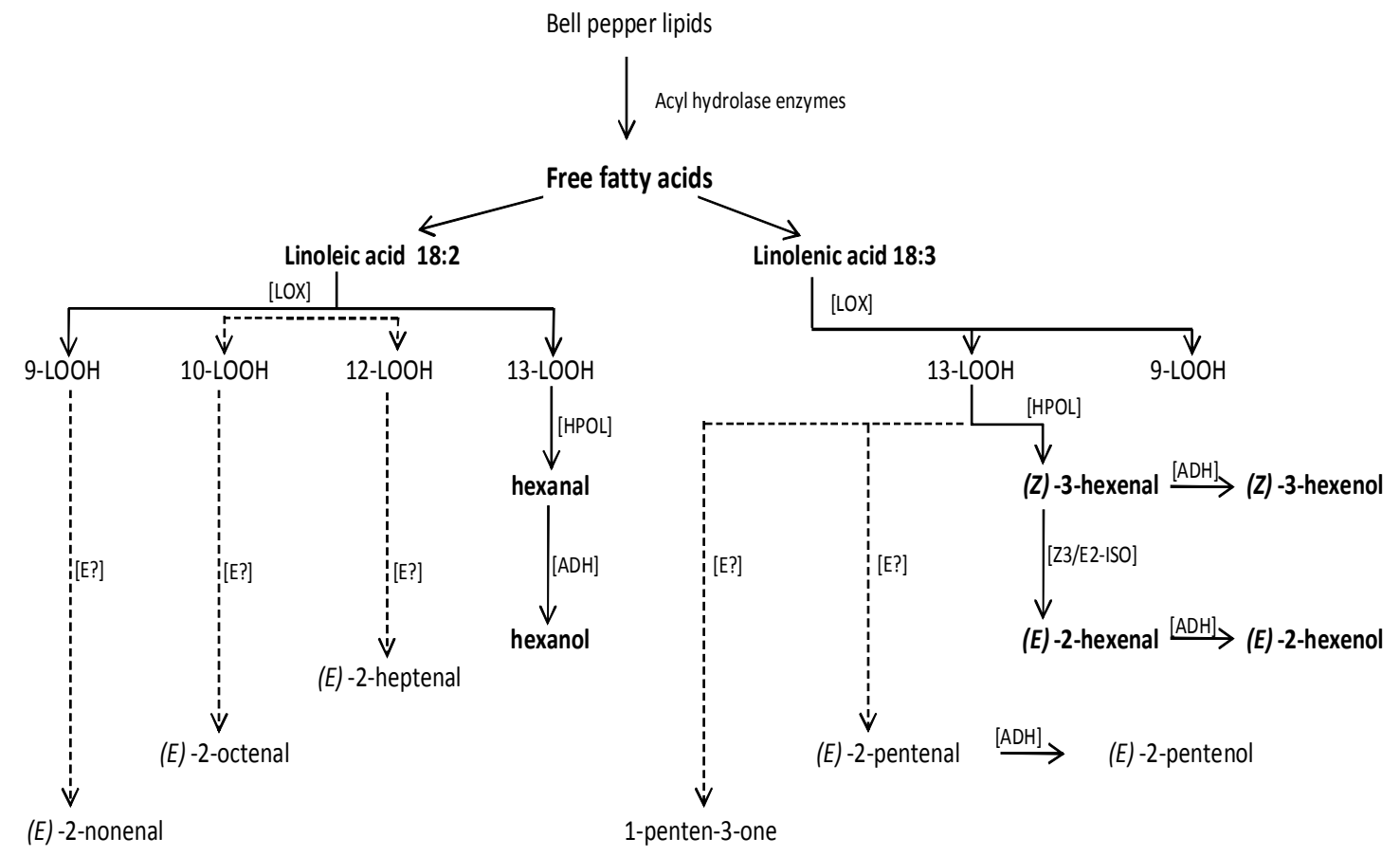

Figure 2.3: Volatile compounds generated by the lipoxygenase pathway proposed for bell peppers. Abbreviations: LOOH, hydroperoxide; [LOX], lipoxygenase; [HPOL], hydroperoxide lyase; [ADH], alcohol dehydrogenase; [Z3/E2-ISO], (Z)-3/(E)-2 isomerase; [E?], unknown enzyme. Source: Luning and others 1995a.

\subsubsection{Effect of Processing on volatile aroma compounds}

Capsicum peppers are processed in different ways including drying, smoking, canning, pickling, and freezing to produce a wide variety of products in response to specific applications. Research has suggested that one of the main factors responsible for changes in volatile aroma compounds of capsicum fruits are the processing techniques (Mateo and others 1997). 


\subsubsection{Drying}

Mateo and others (1997) and Kocsis and others (2002) analyzed the volatile compounds in samples of powdered Paprika, which is a variety of capsicum pepper. The processing to obtain powdered paprika includes drying and milling of the fruits. In the study, compounds responsible for the fresh green bell pepper aroma such as C5-C6 aldehydes and alcohols or 2-methoxy-3-isobutylpyrazine were not found. This result was suggested to be due to inactivation of lipoxygenase enzyme system and to changes in volatiles produced by heating during drying (Mateo and others 1997).

The most abundant compounds of rehydrated diced red bell peppers were: 3methylbutanal, 2-methylbutanal, 3-methylbutiric acid, acetone, and hexanal. Using gas chromatography-olfactometry (GC-O) with 12 trained assessors, 11 active odor compounds were detected. The five compounds with the highest odor intensities were: 2methoxy-3-isobutylpyrazine (bell pepper), hexanal (grassy), 2-/3-methylbutanal (chocolate) and dimethyl trisulphide (rotten, onion/leek). Among the 11 compounds, some are typical for dried vegetables, others formed by Streker degradation and others derived from lipid oxidation (van Ruth and others 2003).

\subsubsection{Canning and Stir frying}

A lower concentration (82\% decrease) of 2-isobutyl-3-methoxypyrazine was found in whole canned jalapeño peppers compared to whole fresh jalapeño peppers. The difference was attributed to the heat involved in processing, which may convert the flavor 
compound in a different one (unknown yet) or partially destroy it. The processed samples exhibited an altered or "cooked" flavor (Huffman and others 1978).

The effect of stir frying on the aroma compounds of bell peppers was evaluated (Wu and others 1986). Stir frying is considered a mild heat treatment. The main changes in the volatile composition are due to a continued autoxidation of unsaturated fatty acids after the stir frying process. The autoxidation of lipids is promoted by heat during the stir frying process. The pathway suggested involves mainly the breakdown of 9Hydroperoxides (Wu and others 1986).

\subsubsection{Blanching}

Some of the quality defects found in dehydrated and frozen unblanched vegetables are the development of off-flavors and off-odors, especially the hay-like aroma, which are attributed to enzyme activity. Blanching is commonly used with the purpose of inactivate enzymes and therefore prevent these quality defects. However; it has been shown that blanching may also result in alteration of desired volatiles. Blanching of green peppers prior to dehydration resulted in a lower hay-like aroma in the dried peppers after an 8-week room temperature storage compared to unblanched peppers. Nonetheless, blanched peppers also resulted in a lower intensity of fresh green pepper aroma and flavor than unblanched peppers (Kuzniar and others 1983). 


\subsubsection{Freezing}

During the freezing process, the formation and propagation of ice crystals inside the vegetable tissue results in the rupture of cell walls which favors the contact between enzymes and their substrates. Additionally, it is known that chemical as well as enzymatic reactions are slowed but not stopped in the phase of liquid water during frozen storage. Lipoxygenase enzyme is responsible for initiating the formation of some aldehydes and alcohols by oxidation of unsaturated fatty acids. These compounds have been related to fresh and green aromas; however, their accumulation during a prolonged frozen storage appears as off-flavors. Then, it is usual to include a blanching step in the production of frozen vegetables in order to avoid off-flavors formation (Nielsen and others 2003).

An increase in hexanal, pentanal, $(E)$-2-monounsaturated aldehydes, $(E, E)$-2,4decadienal, and $(E, E)-2,4-$ nonadienal was found in frozen stored unblanched leeks ($\left.20^{\circ} \mathrm{C}, 12 \mathrm{mo}\right)$, except for $(E)$-2-hexenal which decreased. This was attributed to the continued activity of lipoxygenase pathway enzymes and/or to autoxidation of fatty acids. $(E, E)$-2,4-decadienal and $(E, E)$-2,4-nonadienal have been shown to be very potent offflavors (Nielsen and others 2003). In addition, an increase in ketones, alcohols, acids, and furans was found in frozen stored unblanched leeks. The increase in ketones could be due to autoxidation of polyunsaturated fatty acids (Nielsen and others 2003, 2004a, 2004b). On the other hand, a small but significant increase in aldehydes was found in blanched leeks after frozen storage $\left(-20^{\circ} \mathrm{C}, 12 \mathrm{mo}\right)$. This increase was attributed to autoxidation of fatty acids. The unblanched samples produced 4 times more aldehydes than the blanched 
samples (Nielsen and others 2004b). The specific aroma compounds formed depends on the specificity of the enzymes, for instance in which position lipoxygenase acts and the catalytic activity of hydroperoxide lyase and alcohol dehydrogenase (Nielsen and others 2003).

A higher concentration of aldehydes was found in 4-mm compared to 15-mm sliced unblanched leeks after frozen storage. This could be explained by the higher degree of tissue disruption per weight unit in the 4-mm slices compared to the $15-\mathrm{mm}$ slices (Nielsen and others 2004a).

The volatile-compound profiles of fresh whole, homogenized, frozen and freezedried Padrón-type pepper samples were all different (Oruña-Concha and others 1998). They found that homogenization, freezing and freeze drying methods affected the volatile-component profile of the peppers in a different way. Freezing of whole fresh peppers increased the content of terpenes, pyrazines, and phenols. Homogenization considerably increased the content of aldehydes, esters, pyrazines, and phenols; and produced a loss of ethers, pyrroles, and sulfurous compounds. Freeze drying drastically reduced the compounds increased by homogenization and increased pyrroles content (Oruña-Concha and others 1998).

\subsection{Analysis of Volatile Aroma Compounds}

It was not until the $19^{\text {th }}$ century that scientists started studying the compounds responsible for the pleasant aroma of certain foods, as well as those generated by cooking, baking or roasting (Maarse 1991). During the first half of the $20^{\text {th }}$ century the 
first attempts for identifying the major volatile compounds of various foods products were made (Maarse 1991). After that, significant advances have been made in instrumentation and methodology for the isolation, separation, and identification of volatile compounds in foods, allowing an important increase in knowledge in the field of flavor chemistry (Maarse 1991; Teranishi and others 1999).

\subsubsection{Isolation and Separation techniques}

Fundamental techniques for the isolation and separation of compounds include distillation, extraction, adsorption, and liquid and gas chromatography. The LikensNickerson apparatus that allows simultaneous steam distillation and solvent extraction has been a popular and useful technique. Multiple modifications of the original design have been made to improve efficiency and to tailor to specific situations. In the adsorption method, volatiles are adsorbed on a polymeric material and then desorbed by heat or solvents. Some decomposition of compounds is possible due to the application of heat (Maarse 1991; Teranishi and others 1999).

The objective of isolation is to obtain volatile compounds from the original source with minimum artifacts. Sample preparation techniques should be simple, fast, inexpensive, and compatible with a range of analytical instrumentation in order to avoid errors introduced by the interval time required between sample preparation and solvent extraction steps (Sousa and others 2006). In this way, head space isolation techniques have been developed more recently. Dynamic head space analysis and head space solid phase microextraction (SPME) are important techniques used to isolate compounds 
directly from the vapor phase of the sample according to equilibrium partitioning coefficients. These techniques are simple, fast, efficient, and less prone to introduce artifacts compared to traditional methods. Additionally, these methods reduce losses often produced by concentration or evaporation of solvents (Maarse 1991). However, they also have some disadvantages. For instance, the relative concentration of volatiles in the head space of the sample can be different to that in the absorbent polymer due to differences in the affinity of each volatile compound (Maarse 1991).

Volatile measurement techniques have evolved throughout the years (van Ruth and others 2003). While the volatiles present in the food product were measured in previous years (extraction and distillation methods), now the volatile compounds in the air around the food are measured (in the headspace). This change in the analysis method follows the fact that the sensory perception of aroma is determined by the concentration of volatiles in the air phase rather than in the food product itself. The headspace analysis is more closely related to the conditions in the mouth.

While most studies used hydrodistillation and dynamic headspace sampling, Kim and others (2007) used a direct sample injection technique called Solvent Free Solid Injection (SFSI). Since it has been reported that thermal treatment produces major variations (by chemical or enzymatic reactions) in the aroma composition of peppers, SFSI constitutes an interesting extraction technique to analyze volatiles in peppers in their natural state, without any pretreatment (Kim and others 2007).

Gas chromatography is a potent, very sensitive and reliable technique widely used to separate the complex mixture of volatile compounds present in foods. Since early 
experiments in 1960 up to the present, this technique has enormously contributed to the progress of flavor chemistry (Teranishi and others 1999).

\subsubsection{Identification techniques}

Several spectrometric methods are used for the characterization and identification of flavor compounds. Mass spectrometry is the most popular among them. Coupled with gas chromatography (GC-MS), this technique has been mainly used for the identification of compounds in foods and beverages and responsible for the large amount of information currently available in the field (Maarse 1991; Teranishi and others 1999).

Infrared spectrometry and Nuclear magnetic resonance (NMR) are used for providing "fingerprint" patterns and for determining structure of compounds, respectively. GC-Olfactometry, based on sniffing the effluents from the GC columns, has also been used to help identifying the contribution of individual compounds to the overall aroma of foods, as well as to assign sensorial odor descriptors to chemical compounds. (Teranishi and others 1999).

Finally, continuous improvements and new techniques have evolved from the previous ones, such as "time-of-flight" (TOF) instruments for TOF-based GC-MS, MS/MS, multidimensional GC coupled to mass spectrometry and isotope ratio mass spectrometry (MDGC-MS and MDGC-IRMS). And more recently, development of “chemical ionization" has produced techniques such as ESI-MS/MS (electrospray ionization mass spectrometry), atmospheric pressure chemical ionization mass spectrometry (APCI-MS), proton transfer reaction mass spectrometry (PTR-MS), and selected ion flow tube mass spectrometry (SIFT-MS) among others (Herderich 1999). 
Van Ruth et al. (2003) compared three chromatographic techniques and two direct mass spectrometry techniques for the analysis of volatiles of rehydrated diced red bell peppers. The chromatographic techniques were: gas chromatography-olfactometry (GCO), gas chromatography-flame ionization detection (GC-FID), and gas chromatographymass spectrometry (GC-MS). The direct mass spectrometry techniques were: atmospheric pressure chemical ionization-time-of-flight mass spectrometry (APCI-TOFMS) and proton transfer reaction-mass spectrometry (PTR-MS). The authors conclude that GCMS, GC-FID and PTR-MS resulted in no significantly different proportion of aroma compounds of rehydrated diced red bell peppers. APCI-TOFMS showed more variant results as it correlates less with the other techniques.

For the APCI-TOFMS analysis, some compounds could not be differentiated due to their identical composition, isobaric characteristics and for detection threshold reasons. The authors indicate that ionization in mixtures may be affected if one compound had a greater affinity for protons than another (selective suppression) (van Ruth and others 2003). For the PTR-MS technique, most of the odor active compounds were detected. They discriminated between isobaric compounds using known fragmentation patterns. However, 1-octen-3-one and dimethyl trisulphide isobaric compounds could not be separated or detected due to threshold reasons. 


\subsubsection{Selected Ion Flow Tube - Mass Spectrometry}

SIFT-MS (Selected Ion Flow Tube - Mass Spectrometry) is an emerging mass spectrometric analytical method that allows for detection and quantification of volatile organic compounds in whole-air or breath samples (Syft Technologies 2010).

Originally developed for the study of gas-phase ion chemistry in the early 1990's, this analytical technique has been mainly applied to breath analysis for clinical diagnosis and therapeutic monitoring, as well as for environmental research (Spanel and Smith 1999). However, the application of this technique is gaining popularity in diverse fields, including food science. Spanel and Smith (1999) demonstrated the value of SIFT-MS for the analysis and real-time monitoring of volatiles emitted from cut onion, crushed garlic and ripe banana. In addition, the volatile profile and real-time production of lipid-related volatiles in tomatillo and tomatoes has been analyzed using SIFT-MS (Xu and Barringer 2009, 2010).

SIFT-MS is based on chemical ionization of volatile compounds molecules using three precursor ions: $\mathrm{H}_{3} \mathrm{O}^{+}, \mathrm{NO}^{+}$, and $\mathrm{O}_{2}{ }^{+}$. The precursor ions are generated by microwave gas discharge and selected using a quadrupole mass filter. Afterward, the ions are introduced through a venturi inlet into the reaction chamber - the flow tube- where they flow along to a carrier gas (generally helium) at controlled velocity and pressure. Then, the gas sample is introduced into the flow tube where the volatile compounds present in the sample react with the precursor ions creating specific product ions. Finally, precursor and product ions count rates are determined by a quadrupole mass spectrometer system. A good understanding of ion chemistry, well-defined kinetics database, and 
controlled reaction conditions allows SIFT-MS for absolute quantification of multiple volatile compounds simultaneously and in real-time (Spanel and Smith 1999; Syft Technologies 2010). A SIFT-MS instrument and a schematic representation of its internal processes are shown in Figure 2.3 and Figure 2.4.

The requirement for the method is the previous identification of the product ions formed by the reaction between each of the volatile compounds present in the sample with the selected precursor ion (Spanel and Smith 1999). Reactions between the precursor ions and numerous organic compounds have been studied in previous works. The kinetic data obtained is included in the SIFT-MS software.

The main advantages of SIFT-MS are that no elaborate sample preparation or chromatographic separation is needed minimizing interferences. It allows real-time detection and monitoring of compounds, simpler mass spectra, accurate and sensitive quantification (ppt level) of volatiles, and discrimination of isobaric compounds and isomers by using multiple precursor ions. Additionally, its operation is fast and simple (Spanel and Smith 1999; Syft Technologies 2010). 


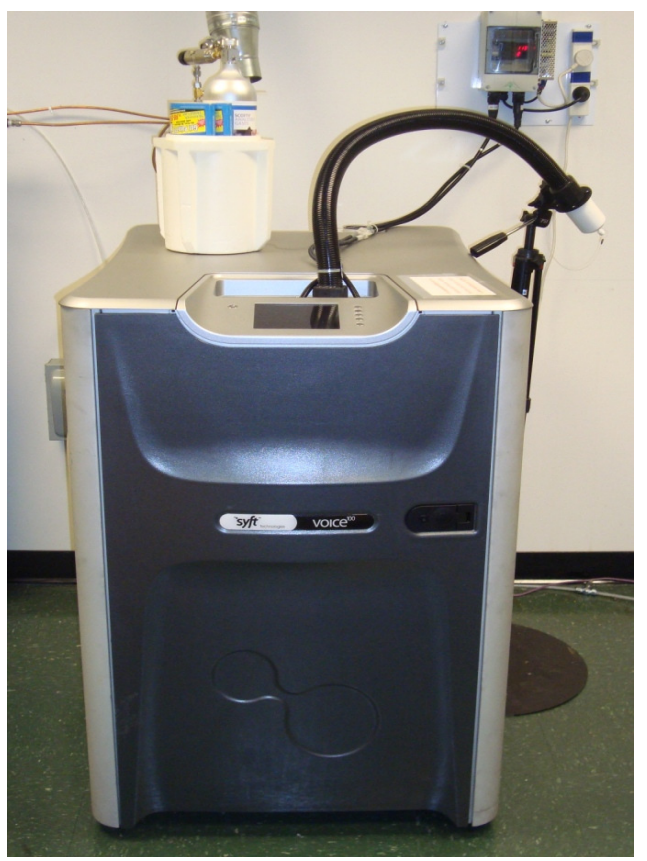

Figure 2.4: SIFT instrument, model Voice 100, Syft Technologies Inc.

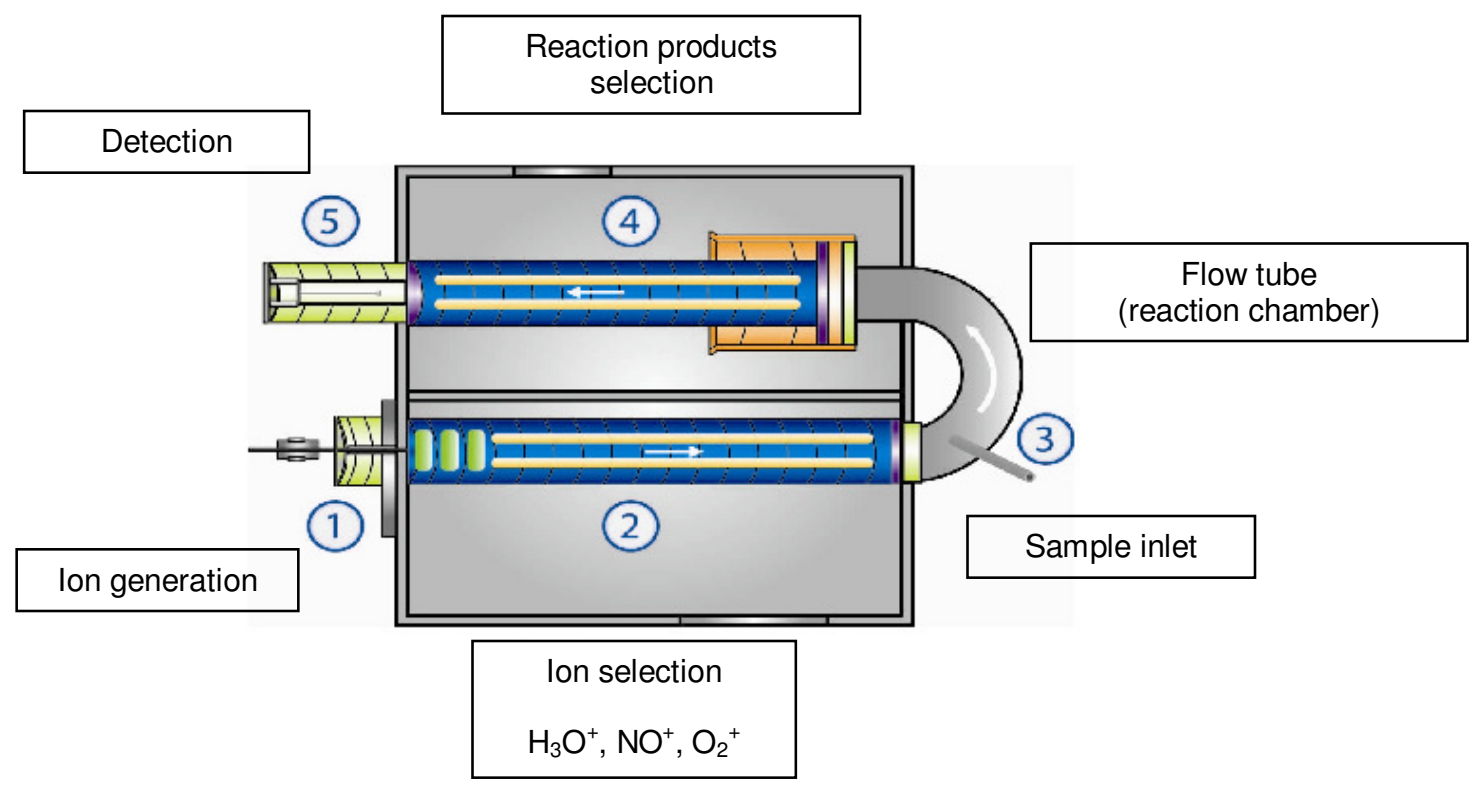

Figure 2.5: Graphic representation of main internal processes of SIFT-MS instrument. Source: Syft Technologies 2010. 


\section{CHAPTER 3}

\section{MATERIALS AND METHODS}

\subsection{Materials}

The mature-green jalapeño peppers used for this research were bought fresh from a local store between March 2009 and January 2010.

\subsection{Sample preparation}

\subsubsection{Blanching}

To blanch peppers, whole fresh peppers were submerged in boiling water for 2.5 min and then allowed to cool at room temperature. Enzyme inactivation was confirmed by a peroxidase test. For the peroxidase test, $2 \mathrm{~g}$ of blanched pepper were crushed in a mortar, and then $0.5 \mathrm{ml}$ of $0.5 \%$ guaiacol in $50 \%$ ethanol, and $0.5 \mathrm{ml} 3 \%$ hydrogen peroxide solutions were added. The crushed pepper and solutions were mixed and allowed to react for $3.5 \mathrm{~min}$. No reddish-brown color formation after $3.5 \mathrm{~min}$ indicated peroxidase inactivation. 


\subsubsection{Effect of enzyme activity on volatile formation}

Whole unblanched or blanched jalapeño peppers with the peduncles cut off were sliced into $2 \mathrm{~cm}$-thick slices and 50g were put into a blender (Waring, Dynamics Corp.) together with $150 \mathrm{ml}$ of distilled water or $0.2 \mathrm{M} \mathrm{SnCl}_{2}$ solution. Peppers were blended for $30 \mathrm{sec}$, and the puree obtained was transferred into a $500 \mathrm{ml}$ glass bottle, capped, and tested for volatiles immediately. The scan time was $10 \mathrm{~min}$. Polybutylene terephtalate (PBT) open top caps coupled to polytetrafluoroethylene (PTFE) faced silicone septa were used. The $0.2 \mathrm{M} \mathrm{SnCl}_{2}$ solution was used to denature the enzymes and inhibit volatile compound generation in unblanched peppers.

\subsubsection{Effect of frozen storage on volatile profile}

Two sets of samples of whole unblanched and blanched (450 g), and pureed unblanched and blanched (120 g) jalapeño peppers were hand-packed in plastic bags, sealed allowing some air in the head space, and stored at $-15^{\circ} \mathrm{C}$. One set was measured for volatiles before and after 1.5, 2.5, and 3 mo of frozen storage only in unblanched samples; whereas the other set was measured before and after 6 and 9 mo of frozen storage in both unblanched and blanched samples. Frozen whole and pureed peppers samples were thawed at $4{ }^{\circ} \mathrm{C}$ for $12 \mathrm{~h}$, and then brought to room temperature in a $25^{\circ} \mathrm{C}$ water bath for ca. $1 \mathrm{~h}$. Whole peppers samples were pureed prior to analysis. Puree was obtained by blending $80 \mathrm{~g}$ of $2 \mathrm{~cm}$-thick slices of pepper with $40 \mathrm{ml}$ of water for $30 \mathrm{sec}$, and then transferred immediately into $500 \mathrm{ml}$ glass bottles. Samples were tested $10 \mathrm{~min}$ 
after blending; or 10 min after transferring into bottles in the case of thawed puree. Bottles were kept capped during the 10 min period. The scan time was 2 min.

\subsection{Analysis of volatile compounds}

The analysis of volatile compounds was performed using a Selected Ion Flow Tube - Mass Spectrometry (SIFT-MS) instrument (SYFT Voice100, Syft Technologies Ltd., Christchurch, New Zealand). The SIFT-MS technology uses soft chemical ionization with three different precursor ions generated by microwave discharge. The product ion count rates are determined by a quadrupole mass spectrometer. The inlet port of the instrument was coupled with an 18 ga $3.8 \mathrm{~cm}$-long stainless steel passivated needle to facilitate piercing and sampling volatiles from the glass bottle headspace. Prepared samples were tested by inserting the needle through the silicone septum fitted in the open top cap of the bottle. The septum was also pierced by a $14 \mathrm{ga} 15 \mathrm{~cm}$-long syringe needle to maintain atmospheric pressure inside the bottle. The tip of the short and long needle was located at ca. $12 \mathrm{~cm}$ and $1 \mathrm{~cm}$ from the surface of the sample, respectively. The background measured for the distilled water or $0.2 \mathrm{M} \mathrm{SnCl}_{2}$ solution used for blending was subtracted from the data. Measurements were performed using selected ion mode (SIM) scans with $\mathrm{H}_{3} \mathrm{O}^{+}, \mathrm{NO}^{+}$, or $\mathrm{O}_{2}{ }^{+}$as precursor ions, calculation delay time $5 \mathrm{~s}$, product sample period $100 \mathrm{~ms}$, precursor sample period $20 \mathrm{~ms}$, carrier gas argon pressure 200 $\mathrm{kPa}$, helium pressure $30 \mathrm{psi}$, capillary and arm temperature $120^{\circ} \mathrm{C}$, and flow tube pressure $0.038 \pm 0.003$ Torr. The SIFT-MS methods used include the main volatiles found in capsicum fruits as reported by previous studies. The kinetic parameters for these 
compounds are provided in Table 3.1. The compound hexenol represents a mixture of (Z)-3-hexenol and $(E)$-2-hexenol; the compounds 2-pentenal is a mixture of $(E)$-2-

pentenal and (Z)-2-pentanal; the compound methylbutanal is a mixture of 2-

methylbutanal and 3-methylbutanal; and terpenes is a mixture of limonene, linalool, ocimene, 2- and 3-carene.

Data from 6 and 9 mo whole unblanched peppers and 6 mo pureed unblanched peppers was normalized based on the 0 mo data on graphs which contain both this and the data from 1.5 to 3 mo of storage.

\subsection{Statistical Analysis}

Data were analyzed using one-way analysis of variance (ANOVA) and Tukey's multiple comparison procedure, and Student's t- test. Significance was defined as $p \leq 0.05$. The number of replicates for each sample was five. Error bars in the graphs represent the standard error of the replicates. 


\begin{tabular}{|c|c|c|c|c|c|c|}
\hline Volatile compound & $\begin{array}{l}\text { Molecular } \\
\text { formula }\end{array}$ & $\begin{array}{c}\text { Precursor } \\
\text { Ion }\end{array}$ & $\begin{array}{c}k \\
\left(10^{-}\right. \\
{ }^{9} \mathrm{~cm}^{3} \mathbf{s}^{-} \\
\left.1^{1}\right)\end{array}$ & $m / z$ & $\begin{array}{l}\text { Product } \\
\text { Ion }\end{array}$ & Ref \\
\hline (E)-2-heptenal & $\mathrm{C}_{7} \mathrm{H}_{12} \mathrm{O}$ & $\mathrm{NO}^{+}$ & 3.9 & 111 & {$\left[\mathrm{C}_{7} \mathrm{H}_{11} \mathrm{O}\right]^{+}$} & {$[4]$} \\
\hline (E)-2-hexenal & $\mathrm{C}_{6} \mathrm{H}_{10} \mathrm{O}$ & $\mathrm{NO}^{+}$ & 3.8 & 71 & {$\left[\mathrm{C}_{4} \mathrm{H}_{7} \mathrm{O}\right]^{+}$} & {$[1]$} \\
\hline (E)-2-nonenal & $\mathrm{C}_{9} \mathrm{H}_{16} \mathrm{O}$ & $\mathrm{NO}^{+}$ & 3.8 & 139 & {$\left[\mathrm{C}_{9} \mathrm{H}_{15} \mathrm{O}\right]^{+}$} & {$[4]$} \\
\hline (E)-2-octenal & $\mathrm{C}_{8} \mathrm{H}_{14} \mathrm{O}$ & $\mathrm{NO}^{+}$ & 4.1 & 125 & {$\left[\mathrm{C}_{8} \mathrm{H}_{13} \mathrm{O}\right]^{+}$} & {$[4]$} \\
\hline$(E, E)$-2,4-decadienal & $\mathrm{C}_{10} \mathrm{H}_{16} \mathrm{O}$ & $\mathrm{H}_{3} \mathrm{O}^{+}$ & 4.9 & $\begin{array}{l}153 \\
171 \\
189\end{array}$ & $\begin{array}{c}{\left[\mathrm{C}_{10} \mathrm{H}_{17} \mathrm{O}\right]^{+}} \\
{\left[\mathrm{C}_{10} \mathrm{H}_{17} \mathrm{O}^{+} .\right.} \\
\left.\mathrm{H}_{2} \mathrm{O}\right] \\
{\left[\mathrm{C}_{10} \mathrm{H}_{17} \mathrm{O}^{+} .\right.} \\
\left.2 \mathrm{H}_{2} \mathrm{O}\right]\end{array}$ & [4] \\
\hline$(E, Z)$-2,6-nonadienal & $\mathrm{C}_{9} \mathrm{H}_{14} \mathrm{O}$ & $\mathrm{NO}^{+}$ & 2.5 & 137 & {$\left[\mathrm{C}_{9} \mathrm{H}_{13} \mathrm{O}\right]^{+}$} & {$[5]$} \\
\hline (Z)-3-hexenal & $\mathrm{C}_{6} \mathrm{H}_{10} \mathrm{O}$ & $\mathrm{H}_{3} \mathrm{O}^{+}$ & 4.2 & 81 & {$\left[\mathrm{C}_{6} \mathrm{H}_{9}\right]^{+}$} & {$[1]$} \\
\hline 1-penten-3-one & $\mathrm{C}_{5} \mathrm{H}_{8} \mathrm{O}$ & $\mathrm{NO}^{+}$ & 2.5 & 114 & $\begin{array}{l}{\left[\mathrm{C}_{5} \mathrm{H}_{8} \mathrm{O} . \mathrm{N}\right.} \\
\mathrm{O}^{+}\end{array}$ & [5] \\
\hline 2,3-butanedione & $\mathrm{C}_{4} \mathrm{H}_{6} \mathrm{O}_{2}$ & $\mathrm{NO}^{+}$ & 1.3 & 86 & {$\left[\mathrm{C}_{4} \mathrm{H}_{6} \mathrm{O}_{2}\right]^{+}$} & [1] \\
\hline $\begin{array}{l}\text { 2-hydroxy-3- } \\
\text { methylpentanoic acid }\end{array}$ & $\mathrm{C}_{6} \mathrm{H}_{12} \mathrm{O}_{3}$ & $\mathrm{NO}^{+}$ & 2.5 & 152 & $\begin{array}{l}{\left[\mathrm{C}_{5} \mathrm{H}_{10} \mathrm{CO}\right.} \\
\text { OH. NO } \\
\end{array}$ & [5] \\
\hline $\begin{array}{l}\text { 2-isobutyl-3- } \\
\text { methoxypyrazine }\end{array}$ & $\mathrm{C}_{9} \mathrm{H}_{14} \mathrm{~N}_{2} \mathrm{O}$ & $\mathrm{H}_{3} \mathrm{O}^{+}$ & 3.0 & 167 & $\begin{array}{c}{\left[\mathrm{C}_{9} \mathrm{H}_{14} \mathrm{~N}_{2} \mathrm{O}\right.} \\
\left.. \mathrm{H}^{+}\right]\end{array}$ & {$[5]$} \\
\hline 2-pentanone & $\mathrm{C}_{5} \mathrm{H}_{10} \mathrm{O}$ & $\mathrm{NO}^{+}$ & 3.1 & 116 & $\begin{array}{c}{\left[\mathrm{C}_{5} \mathrm{H}_{10} \mathrm{O} .\right.} \\
\left.\mathrm{NO}^{+}\right] \\
\end{array}$ & {$[1]$} \\
\hline 2-pentenal & $\mathrm{C}_{5} \mathrm{H}_{8} \mathrm{O}$ & $\mathrm{NO}^{+}$ & 4.0 & 83 & {$\left[\mathrm{C}_{5} \mathrm{H}_{7} \mathrm{O}\right]^{+}$} & {$[4]$} \\
\hline
\end{tabular}

Continued

Table 3.1: Kinetics Parameters for SIFT-MS Analysis of Selected Volatile Compounds References: [1] Spanel and others (2007); [2] Spanel and Smith (1997), [3] Spanel and Smith (1998), [4] Spanel and others (2002), [5] Syft Technologies (2009), [6] Wang and others (2003). 
Table 3.1 Continued

\begin{tabular}{|c|c|c|c|c|c|c|}
\hline acetaldehyde & $\mathrm{C}_{2} \mathrm{H}_{4} \mathrm{O}$ & $\mathrm{O}_{2}^{+}$ & 2.3 & 44 & {$\left[\mathrm{C}_{2} \mathrm{H}_{4} \mathrm{O}\right]^{+}$} & [2] \\
\hline dimethyl disulfide & $\mathrm{C}_{2} \mathrm{H}_{6} \mathrm{~S}_{2}$ & $\mathrm{O}_{2}^{+}$ & 2.3 & 94 & {$\left[\mathrm{C}_{2} \mathrm{H}_{6} \mathrm{~S}_{2}\right]^{+}$} & [3] \\
\hline dimethyl sulfide & $\mathrm{C}_{2} \mathrm{H}_{6} \mathrm{~S}$ & $\mathrm{O}_{2}^{+}$ & 2.2 & 47 & {$\left[\mathrm{CH}_{3} \mathrm{~S}\right]^{+}$} & [3] \\
\hline ethyl acetate & $\mathrm{C}_{4} \mathrm{H}_{8} \mathrm{O}_{2}$ & $\mathrm{NO}^{+}$ & 2.1 & 118 & $\begin{array}{c}{\left[\mathrm{CH}_{3} \mathrm{COOC}_{2} \mathrm{H}_{5}\right.} \\
\left.. \mathrm{NO}^{+}\right]\end{array}$ & [3] \\
\hline guaiacol & $\mathrm{C}_{7} \mathrm{H}_{8} \mathrm{O}_{2}$ & $\mathrm{NO}^{+}$ & 2.5 & 124 & {$\left[\mathrm{C}_{7} \mathrm{H}_{8} \mathrm{O}_{2}\right]^{+}$} & {$[5]$} \\
\hline hexanal & $\mathrm{C}_{6} \mathrm{H}_{12} \mathrm{O}$ & $\mathrm{NO}^{+}$ & 2.5 & 99 & {$\left[\mathrm{C}_{6} \mathrm{H}_{11} \mathrm{O}\right]^{+}$} & [1] \\
\hline hexanol & $\mathrm{C}_{6} \mathrm{H}_{14} \mathrm{O}$ & $\mathrm{NO}^{+}$ & 2.4 & 101 & {$\left[\mathrm{C}_{6} \mathrm{H}_{13} \mathrm{O}\right]^{+}$} & {$[2]$} \\
\hline hexenol & $\mathrm{C}_{6} \mathrm{H}_{12} \mathrm{O}$ & $\mathrm{NO}^{+}$ & 2.5 & 72 & {$\left[\mathrm{C}_{4} \mathrm{H}_{8} \mathrm{O}\right]^{+}$} & {$[5]$} \\
\hline isobutanal & $\mathrm{C}_{4} \mathrm{H}_{8} \mathrm{O}$ & $\mathrm{O}_{2}^{+}$ & 3.0 & 72 & {$\left[\mathrm{C}_{4} \mathrm{H}_{8} \mathrm{O}\right]^{+}$} & {$[4]$} \\
\hline isobutyl alcohol & $\mathrm{C}_{4} \mathrm{H}_{10} \mathrm{O}$ & $\mathrm{O}_{2}^{+}$ & 2.5 & 42 & {$\left[\mathrm{C}_{3} \mathrm{H}_{6}\right]^{+}$} & {$[2]$} \\
\hline methional & $\mathrm{C}_{4} \mathrm{H}_{8} \mathrm{OS}$ & $\mathrm{O}_{2}^{+}$ & 2.5 & 104 & {$\left[\mathrm{C}_{4} \mathrm{H}_{8} \mathrm{OS}\right]^{+}$} & {$[5]$} \\
\hline methyl salicylate & $\mathrm{C}_{8} \mathrm{H}_{8} \mathrm{O}_{3}$ & $\mathrm{O}_{2}^{+}$ & 2.7 & 152 & {$\left[\mathrm{C}_{8} \mathrm{H}_{8} \mathrm{O}_{3}\right]^{+}$} & {$[5]$} \\
\hline methylbutanal & $\mathrm{C}_{5} \mathrm{H}_{10} \mathrm{O}$ & $\mathrm{NO}^{+}$ & 3.0 & 85 & {$\left[\mathrm{C}_{5} \mathrm{H}_{9} \mathrm{O}\right]^{+}$} & {$[4]$} \\
\hline methylbutanoic acid & $\mathrm{C}_{5} \mathrm{H}_{10} \mathrm{O}_{2}$ & $\mathrm{NO}^{+}$ & 2.5 & 132 & {$\left[\mathrm{C}_{5} \mathrm{H}_{10} \mathrm{O}_{2} \cdot \mathrm{NO}^{+}\right]$} & {$[5]$} \\
\hline nonanal & $\mathrm{C}_{9} \mathrm{H}_{18} \mathrm{O}$ & $\mathrm{O}_{2}^{+}$ & 3.2 & 112 & {$\left[\mathrm{C}_{8} \mathrm{H}_{16}\right]^{+}$} & {$[5]$} \\
\hline nonenone & $\mathrm{C}_{9} \mathrm{H}_{16} \mathrm{O}$ & $\mathrm{NO}^{+}$ & 3.3 & 170 & {$\left[\mathrm{C}_{9} \mathrm{H}_{16} \mathrm{O} . \mathrm{NO}^{+}\right]$} & {$[5]$} \\
\hline n-propyl alcohol & $\mathrm{C}_{3} \mathrm{H}_{8} \mathrm{O}$ & $\mathrm{NO}^{+}$ & 2.3 & 59 & {$\left[\mathrm{C}_{3} \mathrm{H}_{7} \mathrm{O}\right]^{+}$} & {$[2]$} \\
\hline n-propyl aldehyde & $\mathrm{C}_{3} \mathrm{H}_{6} \mathrm{O}$ & $\mathrm{NO}^{+}$ & 2.5 & 57 & {$\left[\mathrm{C}_{3} \mathrm{H}_{5} \mathrm{O}\right]^{+}$} & {$[1]$} \\
\hline phenylacetaldehyde & $\mathrm{C}_{8} \mathrm{H}_{8} \mathrm{O}$ & $\mathrm{NO}^{+}$ & 2.5 & 120 & {$\left[\mathrm{C}_{8} \mathrm{H}_{8} \mathrm{O}\right]^{+}$} & {$[5]$} \\
\hline terpenes & $\mathrm{C}_{10} \mathrm{H}_{16}$ & $\mathrm{NO}^{+}$ & 2.2 & 136 & {$\left[\mathrm{C}_{10} \mathrm{H}_{16}\right]^{+}$} & [6] \\
\hline
\end{tabular}




\section{CHAPTER 4}

\section{RESULTS AND DISCUSSION}

\subsection{Effect of enzyme activity on volatile formation}

The concentration of some compounds was monitored in pureed samples of unblanched, unblanched with $0.2 \mathrm{M}$ stannous chloride solution $\left(0.2 \mathrm{M} \mathrm{SnCl}_{2}\right)$, or blanched jalapeño pepper (Figure 4.1). Unblanched samples produced significantly higher concentrations of the compounds $(Z)$-3-hexenal, $(E)$-2-hexenal, hexenol, 2-pentenal, 1penten-3-one, hexanal, hexanol, and (E)-2-heptenal. These compounds are known to be derived from polyunsaturated fatty acids by the action of the lipoxygenase pathway. Several lipoxygenase (LOX) derived compounds such as C6 aldehydes and alcohols have been reported to be responsible for the fresh and green aroma of various fruits and vegetables including capsicum peppers (Luning and others 1994). The tissue disruption of unblanched jalapeño peppers increases the rate of generation of these compounds due to the activity of enzymes involved in the lipoxygenase pathway such as LOX, hydroperoxide lyase (HPOL), (Z)-3/(E)-2 isomerase (Z3/E2 ISO), and alcohol dehydrogenase $(\mathrm{ADH})$ on their substrates. In contrast, the unblanched sample blended with $0.2 \mathrm{M} \mathrm{SnCl}_{2}$ and the blanched sample showed significantly lower concentration of all 
LOX-derived volatiles compared to unblanched samples. The stannous chloride solution was used to chemically inactivate LOX and other enzymes, while blanching thermally denatures the enzymes. Therefore, the generation of LOX-derived volatile compounds was prevented in both stannous chloride-treated and blanched samples due to enzyme inactivation. Wu and Liou (1986) confirmed the inhibition effect of stannous chloride on the enzymatic generation of $\mathrm{C} 6$ aldehydes and alcohols upon tissue disruption of bell peppers.

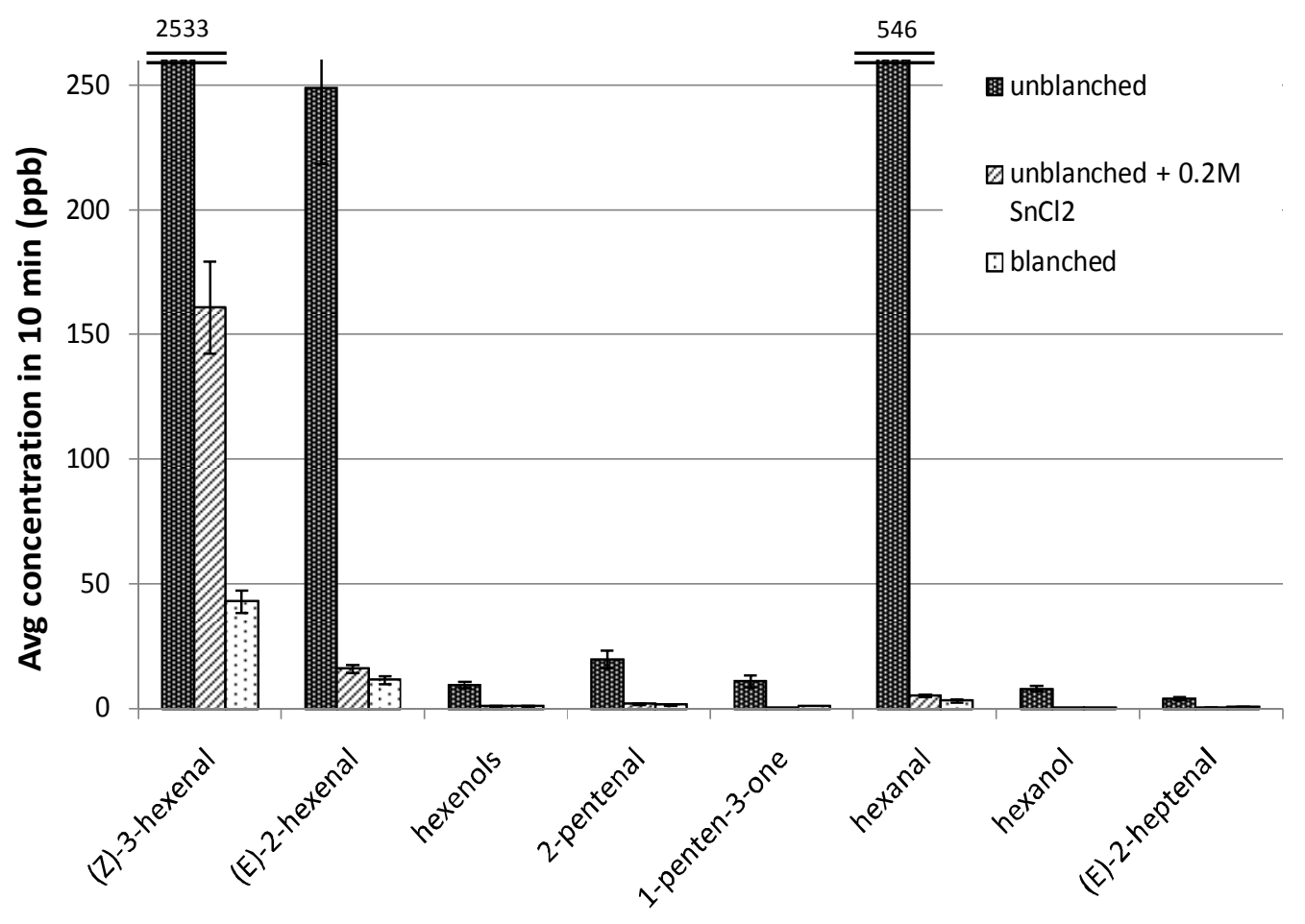

Figure 4.1: Effect of enzyme activity on the concentration of LOX-derived volatiles in jalapeño pepper. Standard error for (Z)-3-hexenal and hexanal in unblanched samples was 384 and 73 , respectively. 
In unblanched samples, the concentration of (Z)-3-hexenal accounted for $75 \%$ of the total concentration of all LOX-derived volatiles tested, while hexanal accounted for $16 \%$, as measured during the initial 10 min after tissue disruption. (Z)-3-Hexenal and hexanal are produced from the 13-hydroperoxide (13-HPO) of linolenic and linoleic acid, respectively (Luning and others 1995a). These aldehydes are the first compounds generated in their respective pathways by the action of LOX and HPOL enzymes.

The ratio of (Z)-3-hexenal to $(E)$-2-hexenal was 10:1 over the first $10 \mathrm{~min}$ after blending, suggesting a faster rate for the generation of (Z)-3-hexenal than for its isomerization into $(E)$-2-hexenal. This ratio is extremely time dependent as the concentration of both compounds vary greatly according to their generation/degradation reactions. In grape tomatoes, the (Z)-3-hexenal to $(E)$-2-hexenal ratio is 1.3:1 over the first 10 min after blending (Xu and Barringer 2009). However, at about $1 \mathrm{~h}$ after blending the ratio is 1.2:1 and 1:28.5 in green and red bell peppers, respectively (Luning and others 1995a); while at about $2 \mathrm{~h}$ after tissue disruption the ratio is 1:34 in bell peppers ( $\mathrm{Wu}$ and Liou 1986). (Z)-3-Hexenal is generated immediately after tissue disruption, and then it starts isomerizing into $(E)$-2-hexenal. Both compounds are converted into their corresponding alcohols. Consequently, the relative concentration of each compound is constantly changing over time; therefore, it is expected that the ratios will be different for these volatiles when measured at different times. If care is not taken, (Z)-3-Hexenal can isomerize to $(E)$-2-hexenal by enzymes present in the medium during the volatile isolation phase in tomatoes (Buttery and others 1987). 
The ratio of the total amount of unsaturated to saturated C6 aldehydes and alcohols was 5:1 over the first 10 min after blending. Hexanal and hexanol are the only saturated C6 volatiles in the reported pathway and they are both primarily produced from linoleic acid, while the unsaturated C6 volatiles (Z)-3-hexenal, $(E)$-2-hexenal, and hexenol are produced from linolenic acid. Thus, the ratio obtained indicates a higher rate of generation of C6 aldehydes and alcohols from linolenic acid than from linoleic acid in jalapeño peppers. Similarly, a ratio of 3:1 in bell peppers at about $2 \mathrm{~h}$ after tissue disruption (Wu and Liou 1986); 2:1 and 5:1 in green and red bell peppers, respectively, at about $1 \mathrm{~h}$ after blending (Luning and others 1995a); and 2.5:1 in grape tomatoes over the first 10 min after blending (Xu and Barringer 2009) has been reported. Unlike the (Z)-3hexenal to $(E)$-2-hexenal ratio, the ratio of the total amount of unsaturated to saturated C6 aldehydes and alcohols is not considerably affected by time. The ratio of linoleic to linolenic acid is ca. 20:1, 7:1, and 27:1 in jalapeño pepper, bell pepper, and tomato, respectively (USDA National Nutrient Database 2010).

\subsubsection{Real-time monitoring of LOX-derived volatiles generation}

The concentration of some LOX-derived volatiles was monitored in real time for 10 min starting 1 min after initiation of blending the peppers.

\subsubsection{1 $(Z)$-3-hexenal and $(E)$-2-hexenal}

The compounds (Z)-3-hexenal and (E)-2-hexenal showed a similar trend (Figure 4.2). The concentration of these compounds was significantly lower in $\mathrm{SnCl}_{2}$-treated and 
blanched samples compared to unblanched samples because enzyme activity was either chemically or thermally inactivated. Then, the concentrations detected correspond to the levels of these volatiles inside the tissue before its disruption. Any increase above these levels is most probably due to additional formation by enzymes upon tissue disruption.

For unblanched samples, high levels of (Z)-3-hexenal and (E)-2-hexenal were generated immediately after tissue disruption, with the highest rate of formation by 1.3 min and 1.5 min after the start of blending for $(Z)$-3-hexenal and $(E)$-2-hexenal, respectively. Since the measurements started $1 \mathrm{~min}$ after initiation of blending, there is already a high concentration of these compounds at the beginning of the testing period. It may be possible that peak concentration occurred within the first minute after tissue disruption. A similar trend in the production of (Z)-3-hexenal and (E)-2-hexenal was observed for grape tomatoes; where the maximum level was reached at 3.3 and $3.7 \mathrm{~min}$ after blending for (Z)-3-hexenal and (E)-2-hexenal respectively (Xu and Barringer 2009). Another study with tomatoes reported the maximum concentration of (Z)-3-hexenal at approximately 3 min after tissue disruption (Buttery and others 1987). This implies a faster LOX activity in jalapeño peppers compared to tomatoes.

The rapid increase in $(Z)$-3-hexenal and $(E)$-2-hexenal is due to a very rapid reaction between enzymes and substrates present in jalapeño pepper. After reaching its peak level, concentration of both compounds declined over time. This can be explained by two factors: the conversion of primary volatiles into different compounds and the depletion of sample headspace. LOX-derived volatiles are constantly changing to other compounds during the testing period. (Z)-3-Hexenal is converted to (E)-2-hexenal by 
Z3/E2 ISO; these aldehydes are reduced to their respective alcohols by ADH (Luning and others 1995a; Xu and Barringer 2009); these changes in compounds constitute the major factor for the declining after peak level. In addition, since the instrument is continuously sampling a volume of the headspace which is replaced by air, this may result in a gradual decrease of the net headspace concentration of these volatiles unless they are being generated at an equivalent rate; however this effect is minimal as almost constant concentrations were observed for $\mathrm{SnCl}_{2}$-treated and blanched samples during the testing period. 


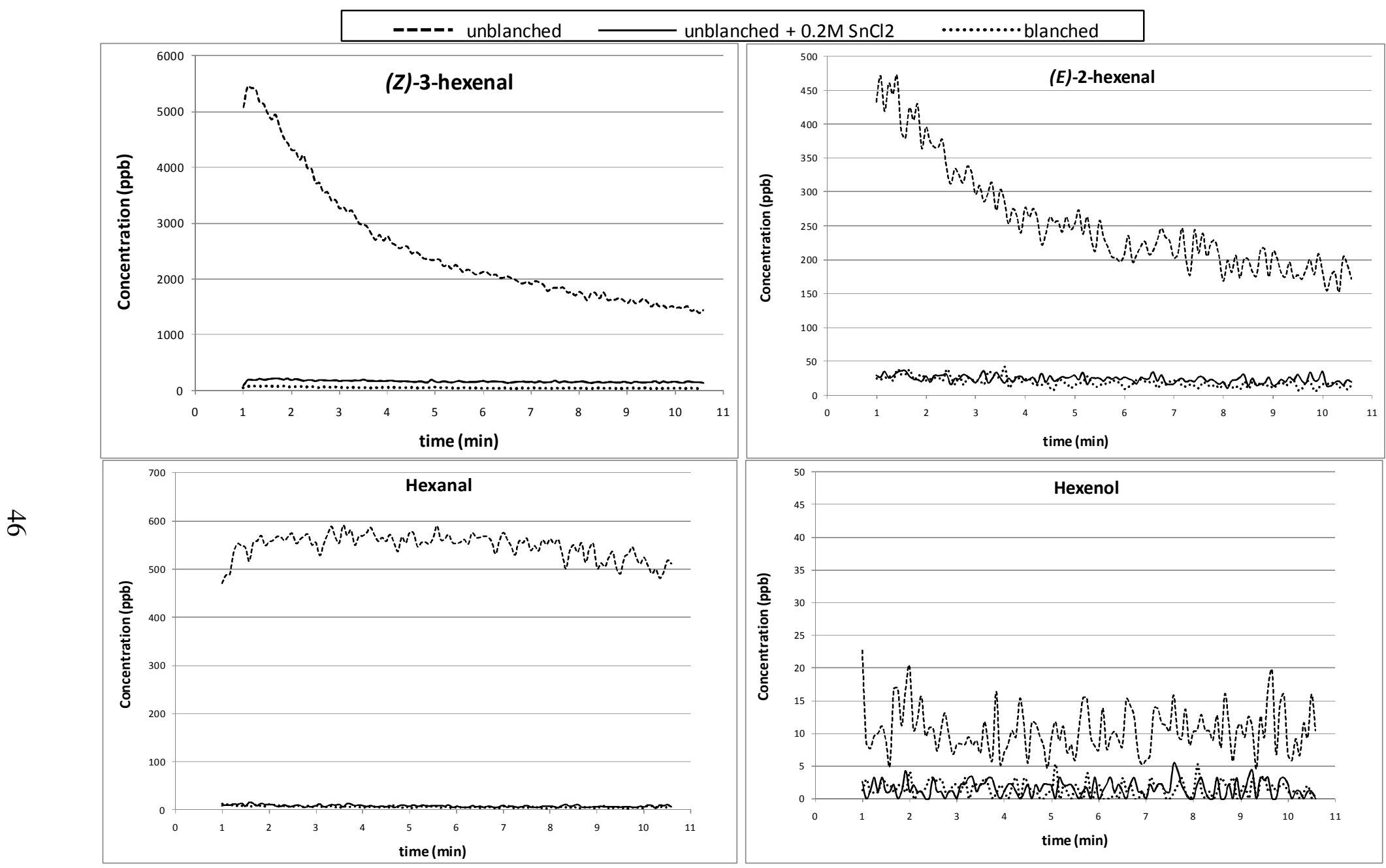

Figure 4.2: Real-time generation of LOX-derived volatiles in unblanched, SnCl2-treated, and blanched jalapeño peppers. 


\subsubsection{Hexanal}

$\mathrm{SnCl}_{2}$-treated and blanched samples represent the levels of hexanal in the intact tissue before disruption. Concentration of hexanal in both samples was significantly lower than the unblanched sample. On the other hand, in unblanched samples the generation of hexanal occurs immediately upon tissue disruption (Figure 4.2). Since the measurements started 1 min after initiation of blending, in unblanched samples there is already a high concentration of hexanal at the beginning of the testing period due to fast enzymatic activity. The concentration of hexanal reached a maximum level at or before 1.5 min after the start of blending. The concentration remained constant for ca. 7 min and then began to decrease. In grape tomato puree, the headspace concentration of hexanal increased after blending, reached a peak level at $4.7 \mathrm{~min}$, and then decreased over time. The decline in hexanal concentration after reaching a maximum level is due to a decrease in the generation rate and to a slow reduction to hexanol (Xu and Barringer 2009).

\subsubsection{Hexenol and hexanol}

Hexenol represents the mixture of $(Z)$-3-hexenol and $(E)$-2-hexenol, which are the corresponding alcohols formed from $(Z)$-3-hexenal and $(E)$-2-hexenal by the action of the enzyme ADH. These isomers cannot be differentiated by SIFT-MS; therefore they are reported together as a mixture. Hexanol is the corresponding alcohol generated from hexanal also by the ADH enzyme (Luning and others 1995a; Xu and Barringer 2009). The results for hexenol and hexanol were similar thus only one is shown (Figure 4.2). For unblanched samples, the concentration was low, around $10 \mathrm{ppb}$ for hexenols and $8 \mathrm{ppb}$ 
for hexanol; however, it was significantly higher than in $\mathrm{SnCl} 2$-treated and blanched sample, indicating enzyme activity. The concentration was roughly constant over the 10 min period tested. Xu and Barringer (2009) also reported a low concentration of hexanol and hexenol in grape tomato puree over a 60 min period after blending. The aldehydes decreased over time; then following the pathway, alcohols should be correspondingly forming. It is possible that the alcohols are quickly converting into other compounds such as acids, and therefore little accumulation is detected.

\section{2 Effect of Blanching on volatiles}

Blanched samples represent the cumulative result of enzymatic inhibition and heating; therefore, differences between blanched and stannous chloride-treated samples can be attributed to the heat effect. There was no significant difference in the concentration of any volatiles between blanched and stannous chloride-treated samples, except for (Z)-3-hexenal (Figure 4.1), methylbutanal and dimethyl sulfide (Figure 4.3). The concentration of (Z)-3-hexenal was higher in the stannous chloride-treated sample compared to the blanched sample. This difference may be attributed to heat degradation during the blanching process. (Z)-3-Hexenal is a heat labile compound. Kazeniac and Hall (1970) reported a poor stability of (Z)-3-hexenal when blended tomatoes were exposed to heat. Heat promotes the isomerization of this compound to $(E)$-2-hexenal. In order to recover $(Z)$-3-hexenal from samples, an isolation technique involving minimal heating is required (Kazeniac and Hall 1970). 
Dimethyl sulfide and methylbutanal had higher concentrations in the blanched sample compared to the stannous chloride-treated sample (Figure 4.3). Dimethyl sulfide was $760 \%$ higher in blanched compared to unblanched peppers. This compound has a cooked, cabbage-like aroma and it is considered key in the aroma of several cooked vegetables (Scherb and others 2009). Together with other volatile sulfur compounds, dimethyl sulfide has been reported to be responsible for the sulfurous off-flavors of several heat-processed foods (Vazquez-Landaverde and others 2005, 2006; Lozano and others 2007). Methylbutanal, which represents the mixture of 2- and 3-methylbutanal, was $86 \%$ higher in blanched compared to unblanched peppers. These compounds have cacao, sweaty, and cooked vegetable odor notes (Luning and others 1995b), and have also been reported to increase concentration in heated products. An increase in 2- and 3methylbutanal was found in bell peppers after hot-air drying (Luning and others 1995b). 2- and 3-Methylbutanal and dimethyl sulfide were predominant odorants in fried chili paste, and their level increased as the heating time increased (Rotsatchakul and others 2008).

Dimethyl sulfide can be formed from the amino acid methionine by Strecker degradation or from $S$-methylmethionine by heat induced breakdown. By Strecker degradation, methional, which is produced from methionine, is decomposed to methanethiol, which then oxidizes to dimethyl sulfide (Lozano and others 2007). Likewise, 2- and 3-methylbutanal are formed by Strecker degradation of isoleucine and leucine respectively, during Maillard reactions (Vazquez-Landaverde and others 2005; Rotsatchakul and others 2008). 
Jalapeño pepper contains the amino acids methionine, leucine, and isoleucine in similar amounts to those found in cabbage and leeks (USDA National Nutrient Database 2010). The heat treatment involved in blanching causes an increase in dimethyl sulfide and methylbutanal in the blanched sample, and may also be responsible for the characteristic aroma that was perceived in blanched peppers during sample preparation, which had less green and fresh notes and more cooked notes compared to unblanched peppers.

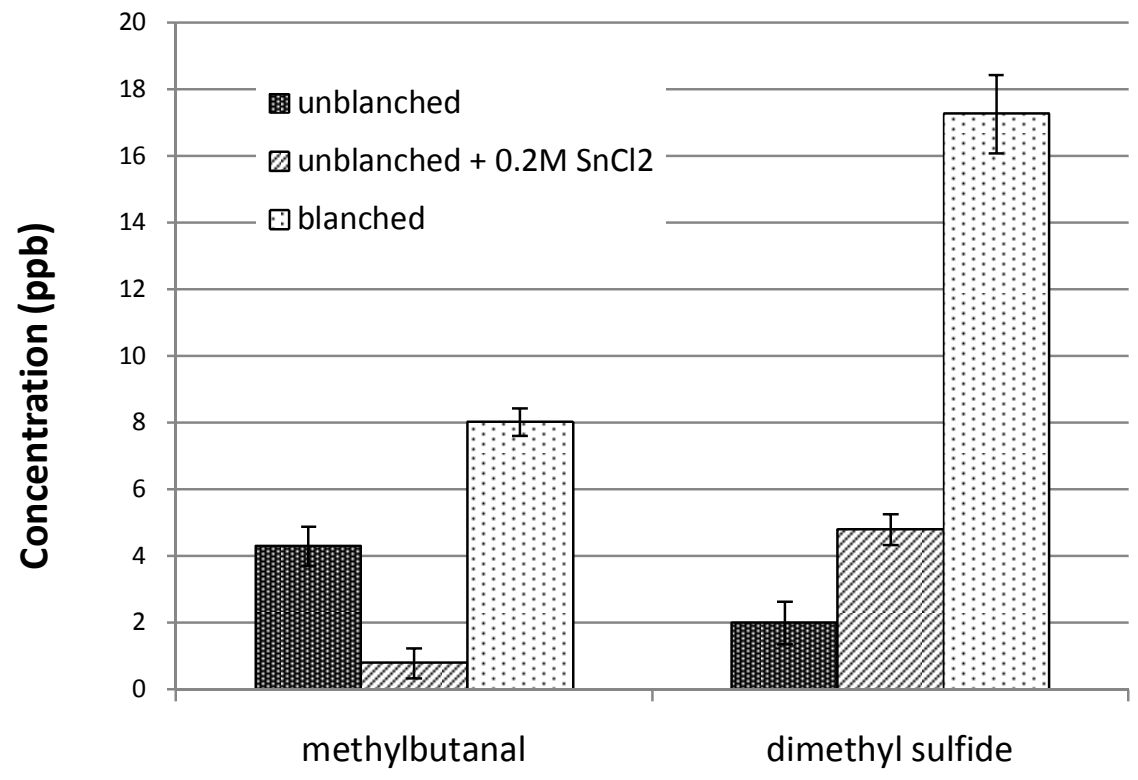

Figure 4.3: Effect of blanching on methylbutanal and dimethyl sulfide. 


\subsection{Effect of frozen storage on LOX-derived volatiles}

The concentration of LOX-derived volatiles was measured in two sets of samples of frozen stored $\left(-15^{\circ} \mathrm{C}\right)$ jalapeño peppers. In one set, volatiles were measured at 0 (initial measurement), 1.5, 2.5, and 3 mo of storage in unblanched samples; whereas in the other set, volatiles were measured at 0,6 and 9 mo of storage in both unblanched and blanched samples. Peppers were stored whole or pureed.

\subsubsection{Blanched peppers}

Since enzymes are inactivated, no major changes were expected in the concentration of LOX-derived volatiles during the frozen storage of blanched samples. There were no major changes in these volatiles during storage time; however, some minor chemical changes were observed, especially in pureed pepper samples (Figure 4.4). In frozen stored leeks, blanching minimized changes in the aroma profile due to inhibited enzymatic activity (Nielsen and Poll 2004).

A decrease in (Z)-3-hexenal accompanied by an increase in $(E)$-2-hexenal over time was found in blanched peppers. This is probably due to a gradual chemical isomerization of $(Z)$-3-hexenal into the more stable $(E)$-2-hexenal. A higher degree of isomerization occurred in the pureed sample compared to the whole pepper sample at the same storage time (6 mo), which was even greater than in whole pepper stored 3 mo longer (9 mo). In pureed samples extensive cell rupture has occurred, favoring greater interaction and exposure of components. The sum of $(Z)$-3-hexenal and $(E)$-2-hexenal concentration did not significantly change for any of the samples tested. This indicates a 
direct conversion of $(Z)$-3-hexenal into $(E)$-2-hexenal throughout the frozen storage period.

The rest of the LOX-generated volatiles maintained their initial concentration during storage, as expected. However, hexanal and 2-pentenal slightly increased concentration in the 6 mo pureed samples. This increase may be due to some autooxidation of linoleic and linolenic acid occurring in the pureed samples where the interaction between the components and oxygen is maximized by tissue breakage and air incorporation resulting from blending. Nielsen and others (2004b) also found a small but significant increase in aldehydes including hexanal, $(E)$-2-pentenal, $(E)$-2-hexenal, and (E)-2-heptenal in frozen stored blanched leeks. The development of aldehydes in the blanched leeks was attributed to autoxidation of polyunsaturated fatty acids. 


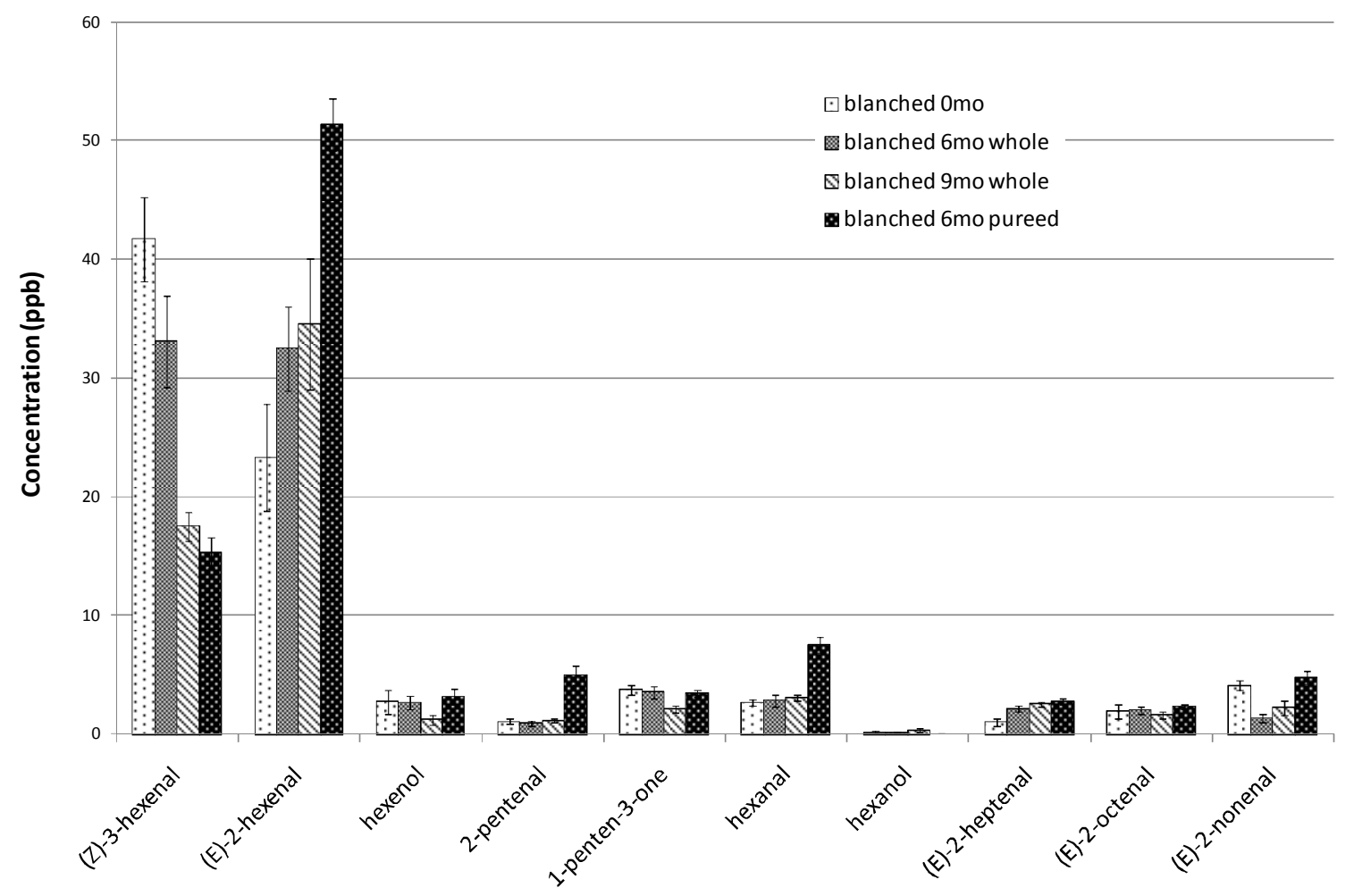

Figure 4.4: Effect of frozen storage on LOX volatiles of whole and pureed blanched jalapeño peppers.

\subsubsection{Unblanched peppers}

\subsubsection{LOX-derived Major volatiles}

During the first three months of frozen storage of the whole pepper samples, $(Z)$ -

3-hexenal gradually decreased concentration over time; while (E)-2-Hexenal maintained its level most probably due to conversion of (Z)-3-hexenal into $(E)$-2-hexenal (Figure 4.5). Hexanal, hexenol, and hexanol decreased in concentration as well. (Z)-3-Hexenal and $(E)$-2-hexenal and their respective alcohol, hexenol, decreased concentration at 6 mo and even further at 9 mo of storage compared to the initial measurement (0 mo) (Figure 
4.6). Hexanal and hexanol also decreased concentration noticeably at 9 mo compared to the initial measurement.

Thus, in the whole unblanched jalapeño peppers (Z)-3-hexenal is generated and then rapidly isomerized to $(E)$-2-hexenal. (E)-2-Hexenal maintained its level over the first 3 mo due to $(Z)$-3-hexenal converting into $(E)$-2-hexenal, but after that it decreases. These aldehydes are then converted to hexenol. In the same way, hexanal is formed and then converted to hexanol. The alcohols, hexenol and hexanol are further degraded into other compounds. However, in whole unblanched jalapeño peppers the degradation rate of these compounds is higher than their generation rate; therefore, they are continuously decreasing over time and not much accumulation occurs.

It is also possible that under these storage conditions the precursors for these compounds go through alternative pathways to form different compounds instead of (Z)3-hexenal and hexanal. This will be discussed in the next section. Differences in compounds concentration between the two set of samples are due to natural variations among different batches of peppers.

Enzymes are active in unblanched peppers and even though their activity is reduced at low temperatures it is not completely stopped. LOX in leeks gradually decreases activity during frozen storage at $-20^{\circ} \mathrm{C}$; however, $25 \%$ of the initial activity was still detected after 12 mo of storage (Nielsen and others 2003). Furthermore, during the freezing process cell structure is damaged by growing ice crystals allowing interaction between LOX enzymes and its substrate polyunsaturated fatty acids which are located in the cytosol and the cell membrane, respectively. During frozen storage 
reactions can take place in the liquid water phase (Nielsen and others 2003, 2004a).

Hence, slow but continued LOX-initiated reactions were expected to occur during the frozen storage of unblanched jalapeño peppers.
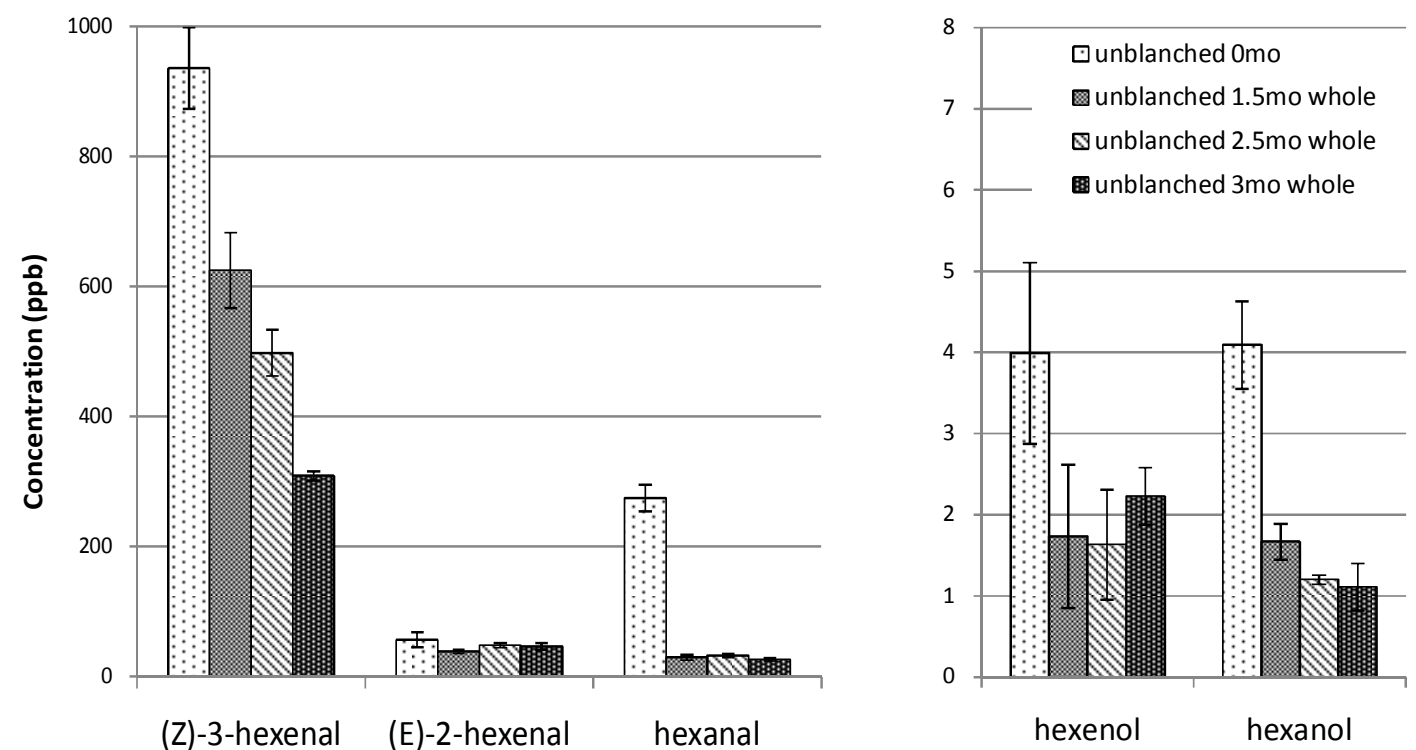

Figure 4.5: Effect of frozen storage on major LOX aldehydes and their corresponding alcohols in whole unblanched jalapeño peppers from 0 to 3 mo. 

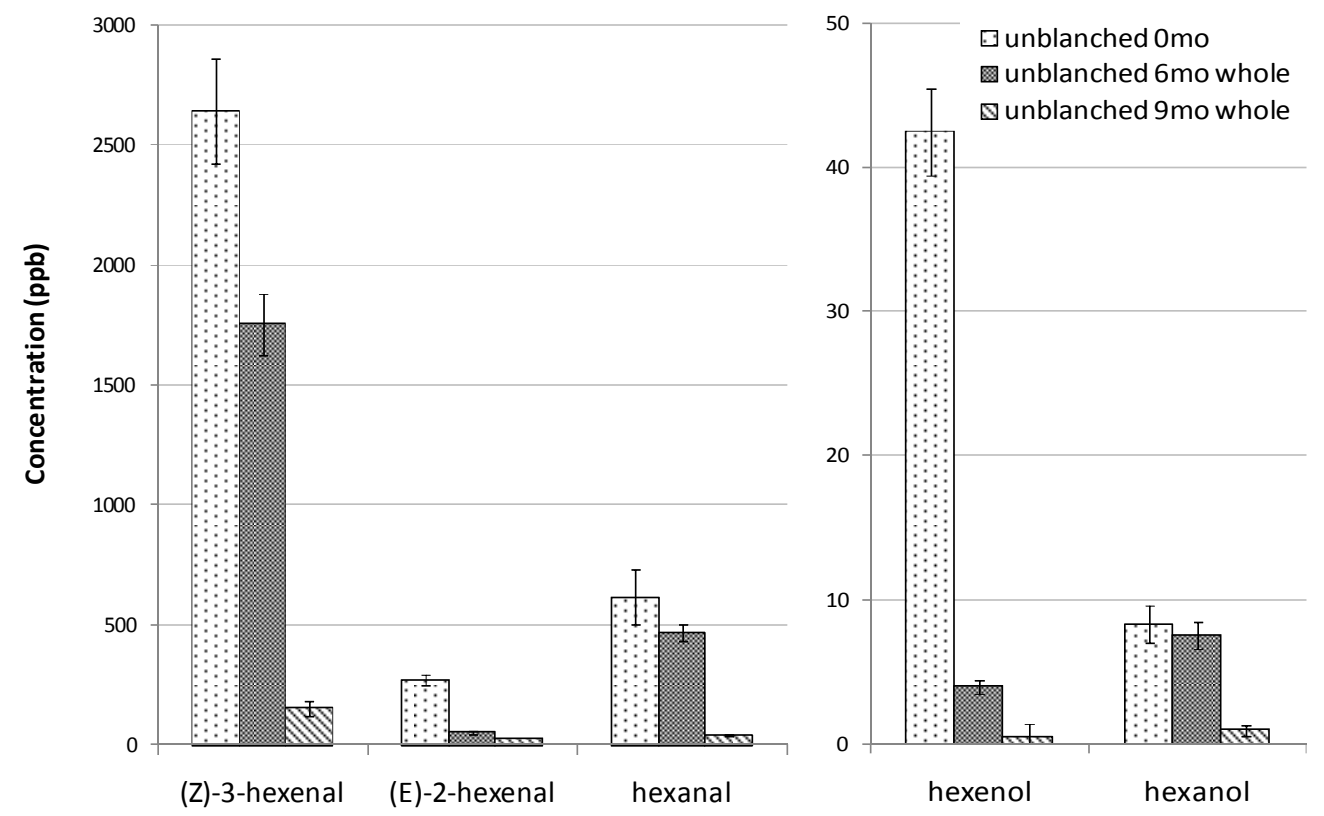

Figure 4.6: Effect of frozen storage on major LOX aldehydes and their corresponding alcohols in whole unblanched jalapeño peppers at 6 and 9 mo.

The behavior of the pureed pepper samples was similar to that of whole pepper samples, except that an early peak occurred in all compounds (Figure 4.7). The concentration of $(Z)$-3-hexenal, $(E)$-2-hexenal, and hexanal increased, reached a maximum level and then decreased over time. Again, (Z)-3-hexenal is generated and then gradually converted into $(E)$-2-hexenal which maintains its concentration from 1.5 to 3 mo. (Z)-3-Hexenal and (E)-2-hexenal are further transformed into hexenol. Hexanal increases concentration and then it is converted to hexanol. Similarly, in unblanched sliced leeks hexanal considerably increased concentration during frozen storage most probably due to polyunsaturated fatty acids oxidation by the lipoxygenase pathway (Nielsen and others 2003). 
Hexenol and hexanol followed the same trend; they were generated and then gradually degraded into other compounds.

In pureed peppers all reactions should occur faster and to a greater extent than in whole peppers due to an increased interaction between components and oxygen, which favors enzymatic and chemical reactions; whereas in whole peppers this interaction is limited. Therefore, during frozen storage, generation of the LOX-derived compounds occurs at a higher rate compared to whole samples which explain the initial increase in concentration for all these compounds in the pureed samples. In frozen stored leeks, LOX activity and consequently LOX-derived aldehydes and alcohols generation was more favorable in 4-mm slices than in 15-mm slices due to a higher degree of cell disruption per weight unit (Nielsen and others 2004a).
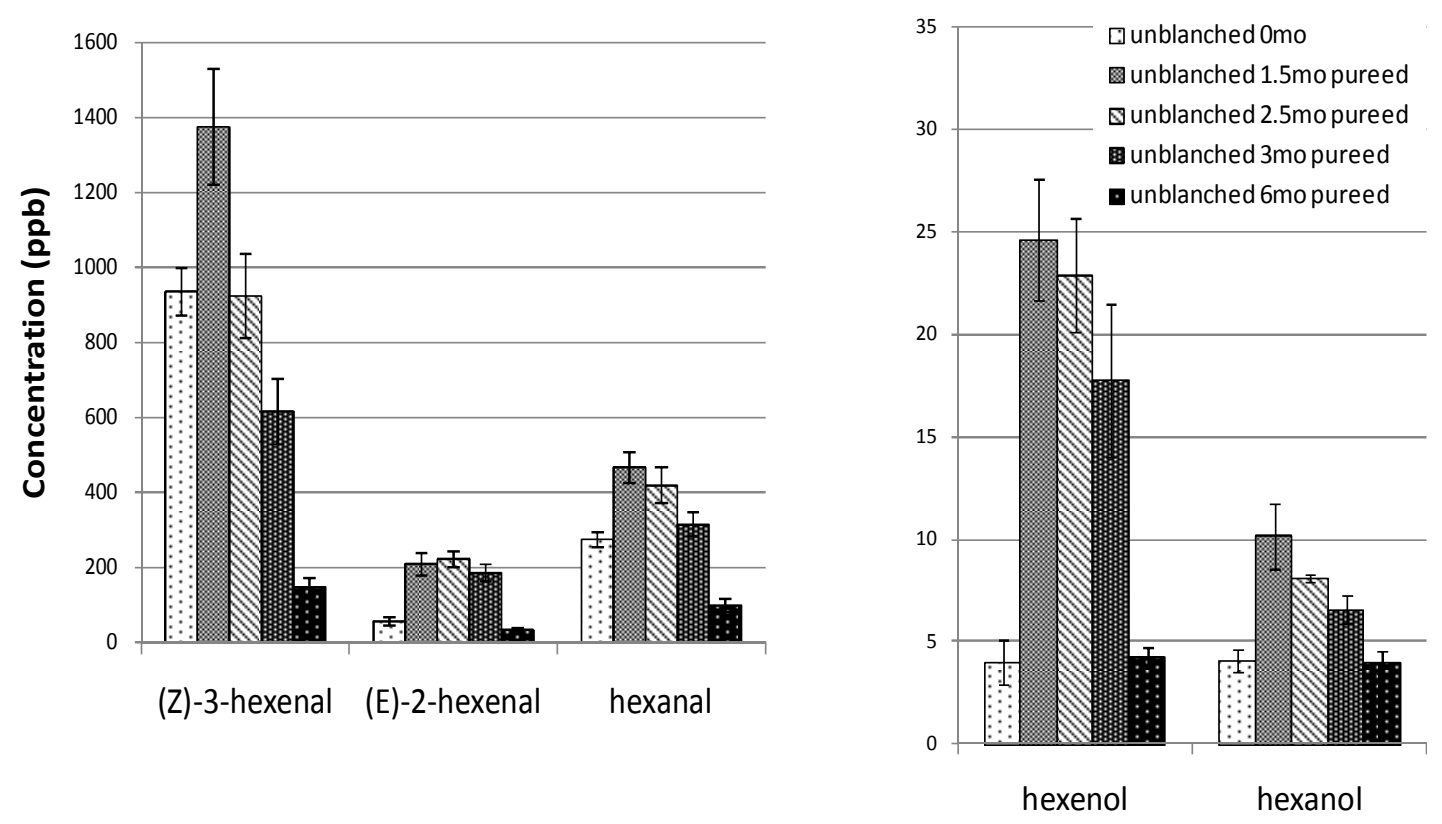

Figure 4.7: Effect of frozen storage on major LOX aldehydes and their corresponding alcohols in pureed unblanched jalapeño peppers. 


\subsubsection{LOX-derived Minor volatiles}

In whole peppers, the minor LOX-derived volatiles 1-penten-3-one, $(E)-2$ heptenal, $(E)$-2-octenal, and $(E)$-2-nonenal gradually increased over the first months of storage reaching a maximum concentration at about $2.5 \mathrm{mo}$, depending on the volatile, and then started decreasing (Figure 4.8). 2-Pentenal and 1-penten-3-one are formed from the 13-HPO of linolenic acid by an alternate pathway proposed in a previous study on bell peppers (Luning and others 1995). (E)-2-Heptenal, $(E)$-2-octenal, and (E)-2-nonenal are formed from the 12-HPO, 10-HPO, and 9-HPO of linoleic acid, respectively. The 12HPO and 10-HPO are formed by a rearrangement of the 13-HPO and 9-HPO of linoleic acid (Luning and others 1995a).

These minor LOX-derived compounds are continuously generating and degrading during storage; however, the relative rate of these reactions throughout storage results in a net increase or decrease in concentration. Similarly, in unblanched leeks, an increase in (E)-2-monounsaturated aldehydes including $(E)$-2-pentenal, $(E)$-2-heptenal, $(E)$-2octenal, and (E)-2-nonenal during frozen storage was also reported. Most of these compounds were not present in the fresh leek but were formed during storage (Nielsen and others 2003).

The behavior of the pureed pepper samples was similar to that of whole pepper samples (Figure 4.9). However, for some compounds the maximum concentration tended to occur a little earlier in pureed peppers than in whole peppers. The maximum concentration of $(E)$-2-heptenal and $(E)$-2- nonenal was reached after 1.5 to 2.5 mo of frozen storage compared to about 3 mo for whole pepper samples. This may be 
explained again by the higher rate of generation and degradation reactions in tissue disrupted peppers.

Results suggest that under the frozen storage conditions tested, there is a slower but continued activity of the alternative 9-HPO, 10-HPO, and 12-HPO pathway for linoleic acid and 13-HPO alternative pathway for linolenic acid proposed by Luning and others (1995a) in previous studies with bell peppers. An increase in the generation rate of $(E)$-2-pentenal, $(E)$-2-heptenal and $(E)$-2-octenal in grape tomato puree at $37^{\circ} \mathrm{C}$ suggested an increase in the activity of alternate pathways at this temperature which may reduce the availability of precursors for the formation of hexanal and (Z)-3-hexenal (Xu and Barringer 2009). Then, in the frozen stored jalapeño peppers the activity of these alternate pathways may also be reducing the availability of precursors for the formation of (Z)-3-hexenal and hexanal, which might explain their low concentration in unblanched whole peppers. 


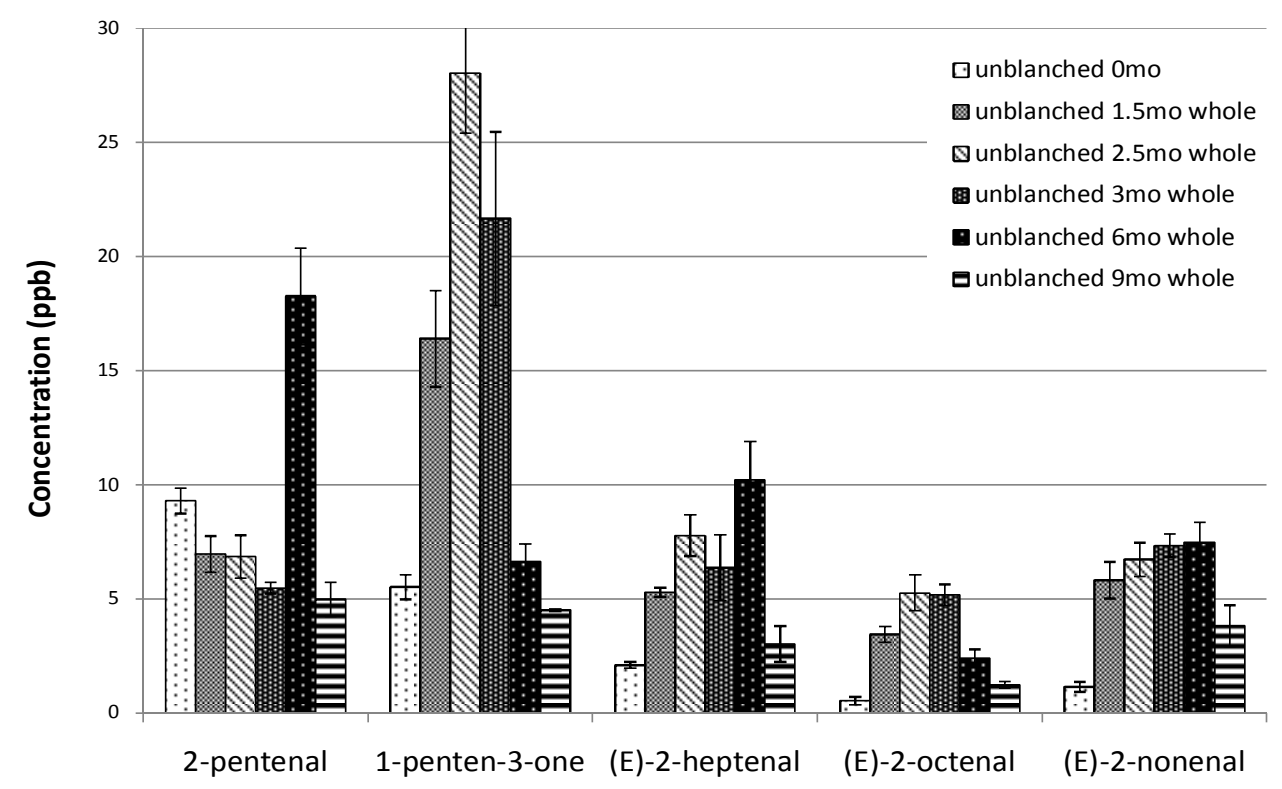

Figure 4.8: Effect of frozen storage on minor LOX volatiles of whole unblanched jalapeño peppers.

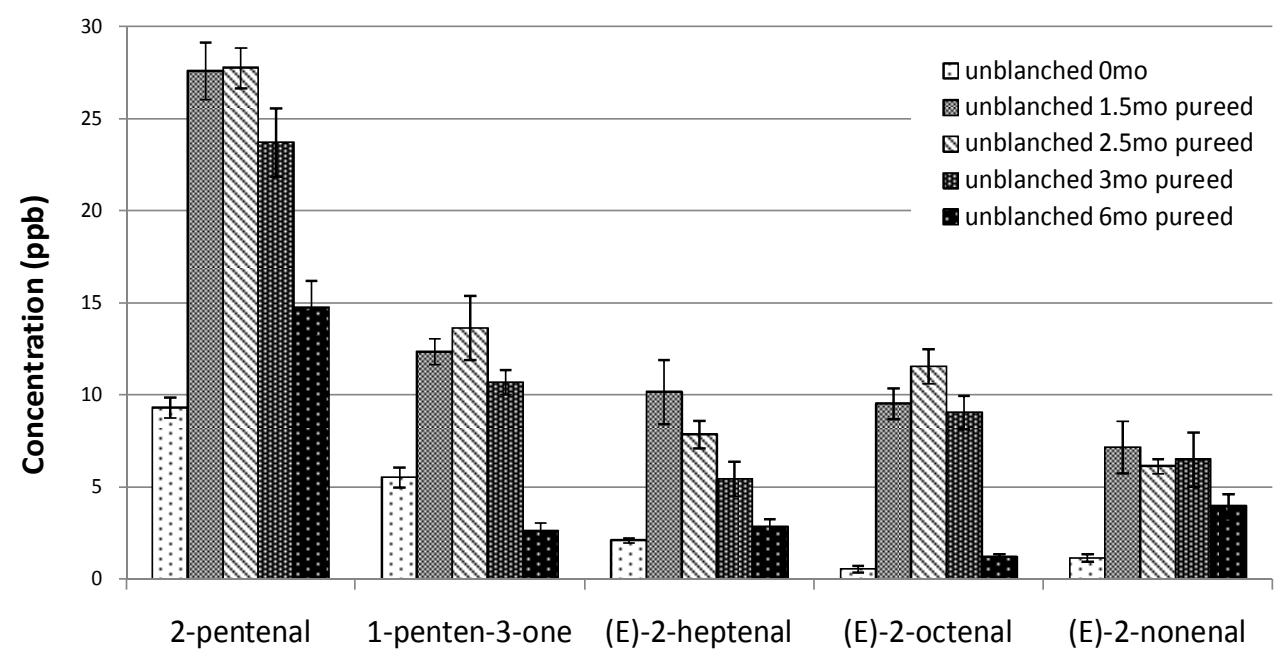

Figure 4.9: Effect of frozen storage on minor LOX volatiles of pureed unblanched jalapeño peppers. 


\subsection{Effect of frozen storage on other volatiles}

The concentration of other volatiles in jalapeño pepper also changed during frozen storage (Table 4.1). Levels of 2-isobutyl-3-methoxypyrazine, n-propyl aldehyde, and a mixture of terpenes decreased over time in both unblanched and blanched peppers indicating a chemical degradation of these compounds under frozen storage conditions. Aldehydes may be converted into alcohols or even further into acids. Terpenes may be attacked by hydroperoxides to form terpene-related ketones and alcohols (Kazeniac and Hall 1970). Conversely, an increase in terpenes and 2-isobutyl-3-methoxypyrazine was found in frozen Padrón -type peppers; however, lot variability made it difficult to identify a characteristic volatile profile for the frozen peppers (Oruña-Concha and others 1998). 2-Isobutyl-3-methoxypyrazine has been associated to the aroma of fresh green bell pepper, and the terpenes analyzed in jalapeño pepper samples, which are a mixture of limonene, linalool, ocimene, and 2- and 3-carene, are related to citrus, floral, and sweaty odor notes (Buttery and others 1969; Chitwood and others 1983).

The compounds nonanal and methylbutanal increased concentration only in unblanched samples suggesting enzymatic formation of these volatiles. An increase in nonanal in frozen stored unblanched leeks was attributed to enzyme activity (Nielsen and others 2003). Similarly, the formation of 3-methylbutanal from the amino acid L-leucine using enzyme extracts from tomatoes was reported (Yu and others 1968). Nonanal has painty and turpentine-like odor notes; while methylbutanal have cacao and cooked vegetable odor notes (Luning and others 1995b; Nielsen and Poll 2004). 
Thus, results suggest an effect of frozen storage on the volatile profile of both unblanched and blanched jalapeño peppers, independently to that produced by the LOX pathway. Differences in volatile concentrations between unblanched and blanched samples may be due to both, enzymatic formation and heat degradation. 


\begin{tabular}{|c|c|c|c|c|c|c|c|c|}
\hline \multirow[b]{2}{*}{ Compound } & \multicolumn{4}{|c|}{ Unblanched } & \multicolumn{4}{|c|}{ Blanched } \\
\hline & $0 \mathrm{mo}$ & 6 mo whole & 9 mo whole & 6 mo pureed & $0 \mathrm{mo}$ & 6 mo whole & 9 mo whole & 6 mo pureed \\
\hline$(E, E)$-2,4-decadienal & 27.0 & 5.1 & $\overline{5.8}$ & 13.0 & 2.0 & 1.3 & 1.5 & 2.9 \\
\hline (E,Z)-2,6-nonadienal & 52.7 & 82.5 & 25.5 & 40.0 & 25.4 & 7.9 & 7.9 & 12.1 \\
\hline 2,3-butanedione & 7.9 & 14.1 & 14.7 & 11.2 & 4.6 & 1.5 & 3.5 & 2.5 \\
\hline 2-hydroxy-3-methylpentanoic acid & 47.7 & 14.7 & 23.2 & 24.9 & 2.3 & 2.9 & 1.2 & 4.1 \\
\hline 2-isobutyl-3-methoxypyrazine & 11.4 & 4.7 & 3.5 & 7.6 & 7.3 & 1.7 & 2.4 & 2.4 \\
\hline 2-pentanone & 67.9 & 4.7 & 2.2 & 25.2 & 1.8 & 1.0 & 1.2 & 2.7 \\
\hline acetaldehyde & 154 & 118 & 13.1 & 45.0 & 3.9 & 3.9 & 4.5 & 1.9 \\
\hline dimethyl disulfide & 16.7 & 39.0 & 9.2 & 18.7 & 11.4 & 4.0 & 5.0 & 8.0 \\
\hline dimethyl sulfide & $<1$ & 272 & 9.4 & 94.7 & 17.2 & 11.8 & 8.0 & 60.0 \\
\hline ethyl acetate & 26.3 & 42.6 & 2.1 & 44.2 & 1.6 & $<1$ & $<1$ & $<1$ \\
\hline guaiacol & 42.9 & 4.2 & 3.3 & 3.4 & 2.4 & 1.2 & 1.4 & 1.9 \\
\hline isobutanal & 82.4 & 8.0 & 3.0 & 24.6 & $<1$ & 3.5 & 1.4 & 4.4 \\
\hline isobutyl alcohol & 106 & $<1$ & 1.8 & 11.2 & $<1$ & $<1$ & 3.0 & $<1$ \\
\hline methional & 7.3 & 11.4 & 5.5 & 19.1 & 1.5 & 1.9 & 2.4 & 2.5 \\
\hline methyl salicylate & 17.2 & 10.6 & 11.8 & 21.1 & 2.4 & 2.6 & 1.1 & 1.9 \\
\hline methylbutanal & 6.7 & 20.4 & 7.8 & 33.2 & 14.4 & 8.2 & 7.0 & 17.8 \\
\hline methylbutanoic acid & 7.6 & 1.7 & 1.9 & 10.8 & 4.6 & $<1$ & 2.1 & $<1$ \\
\hline nonanal & 19.8 & 59.6 & 16.8 & 181 & 5.2 & 4.2 & 8.3 & 49.4 \\
\hline nonenone & 12.6 & 5.9 & 7.4 & 23.2 & $<1$ & $<1$ & $<1$ & 7.0 \\
\hline n-propyl alcohol & 20.1 & 2.2 & 1.8 & 1.7 & 1.5 & 1.0 & 1.8 & $<1$ \\
\hline n-propyl aldehyde & 18.5 & 8.1 & 8.5 & 2.1 & 6.6 & $<1$ & 4.4 & $<1$ \\
\hline phenylacetaldehyde & 8.8 & 4.3 & 2.3 & 12.2 & 1.4 & $<1$ & $<1$ & 2.1 \\
\hline terpenes & 199 & 197 & 45.6 & 60.2 & 119 & 35.7 & 38.8 & 46.7 \\
\hline
\end{tabular}

Table 4.1: Effect of frozen storage on some volatiles in whole and pureed, unblanched and blanched jalapeño peppers. 


\section{CHAPTER 5}

\section{CONCLUSIONS}

Results confirmed that the lipoxygenase pathway is essential for the development of "fresh" and "green" aroma compounds in jalapeño pepper. The generation of these compounds occurs very fast, reaching a maximum concentration within the first $1.5 \mathrm{~min}$ after tissue disruption. The ability of SIFT-MS to measure volatiles in real-time directly from the headspace of samples is crucial to determine the generation and transformation trends of these compounds immediately after the reactions are initiated.

Blanching affected the volatile profile of jalapeño pepper by both enzyme inactivation and a thermal effect. It markedly prevented the generation of LOX-derived compounds due to enzyme inactivation; and at the same time, it resulted in an increased concentration of compounds with "cooked" and "cabbage-like" notes due to heating.

Frozen storage at $-15^{\circ} \mathrm{C}$ resulted in changes in the LOX-derived volatiles of unblanched jalapeño peppers due to a continued enzymatic activity. In contrast, no major enzymatic changes were observed in the volatiles of blanched jalapeño peppers. Pureed pepper samples showed an increased rate of generation and degradation reactions than whole pepper samples due to a greater degree of tissue disruption. 
Similar changes in non-enzymatic volatiles in both unblanched and blanched peppers suggest an effect of frozen storage on the aroma profile of jalapeño pepper additional to that produced by enzymatic activity. 


\section{REFERENCES}

Bosland PW, Votava EJ. 2000. Peppers: vegetable and spice capsicums. New York: CABI Publishing. $204 \mathrm{p}$.

Buttery RG, Seifert RM, Guadagni DG, Ling L. 1969. Characterization of some volatile constituents of bell peppers. J Agric Food Chem 17(6):1322-1327.

Buttery RG, Teranishi R, Ling LC. 1987. Fresh tomato aroma volatiles: a quantitative study. J Agric Food Chem 35(4):540-544.

Castro SM, Saraiva JA, Lopes-da-Silva JA, Delgadillo I, Loey AV, Smout C, Hendrickx M. 2008. Effect of thermal blanching and of high pressure treatments on sweet green and red bell pepper fruits (Capsicum annuиm L.). Food Chem 107(4):14361449.

Chen G, Hackett R, Walker D, Taylor A, Lin Z, Grierson D. 2004. Identification of a specific isoform of tomato lipoxygenase (TomloxC) involved in the generation of fatty acid-derived flavor compounds. Plant Physiol 136(1):2641-2651.

Chitwood RL, Pangborn RM, Jennings W. 1983. GC/MS and sensory analysis of volatiles from three cultivars of capsicum. Food Chem 11(3):201-216.

Eshbaugh WH. 1975. Genetic and biochemical systematic studies of chili peppers (Capsicum- Solanaceae). Bulletin of the Torrey Botanical Club 102(6):396-403.

Forero MD, Quijano CE, Pino JA. 2009. Volatile compounds of chile pepper (Capsicum annuит L. var. glabriusculum) at two ripening stages. Flavour and Fragr J 24(1):25-30.

Galicia-Cabrera RM. 2006. Technologies for jalapeño pepper preservation. In: Hui YH, editor. Handbook of science, technology, and engineering volume 4. Florida: CRC Press. p. 182-1-182-12. 
Govindarajan VS. 1985. Capsicum-production, technology, chemistry, and quality. Part I: History, botany, cultivation, and primary processing. CRC Crit Rev Food Sci Nutr 22(2):109-176.

Haymon LW, Aurand LW. 1971. Volatile constituents of tabasco peppers. J Agric Food Chem 19(6):1131-1134.

Herderich M. 1999. Mass spectrometry in flavor chemistry. In: Teranishi R, Wick EL, Hornstein I, editors. Flavor chemistry: thirty years of progress. New York: Springer. p 9-17.

Huffman VL, Schadle ER, Villalon B, Burns EE. 1978. Volatile components and pungency in fresh and processed jalapeno peppers. J Food Sci 43(6):1809-1811.

Kazeniac SJ, Hall RM. 1970. Flavor chemistry of tomato volatiles. J Food Sci 35(3):519530.

Keller U, Flath RA, Mon TR, Teranishi R. 1981. Volatiles from red pepper (Capsicum spp.). ACS Symp Ser - ACS 170:137-146.

Kim I, Abd El-Aty AM, Shin H, Lee HB, Kim I, Shim J. 2007. Analysis of volatile compounds in fresh healthy and diseased peppers (Capsicum annuum L.) using solvent free solid injection coupled with gas chromatography-flame ionization detector and confirmation with mass spectrometry. J Pharm Biomed Anal 45(3):487-494.

Kocsis N, Amtmann M, Mednyánszky Z, Korány K. 2002. GC-MS investigation of the aroma compounds of hungarian red paprika (Capsicum annuum) cultivars. J Food Compos Anal 15(2):195-203.

Kuzniar A, Bowers JA, Craig J. 1983. Ascorbic acid and folic acid content and sensory characteristics of dehydrated green peppers. J Food Sci 48(4):1246-1249.

Lozano PR, Drake M, Benitez D, Cadwallader K. 2007. Instrumental and sensory characterization of heat-induced odorants in aseptically packaged soy milk. J Agric Food Chem 55(8):3018-3026.

Luning PA, Carey AT, Roozen JP, Wichers HJ. 1995a. Characterization and occurrence of lipoxygenase in bell peppers at different ripening stages in relation to the formation of volatile flavor compounds. J Agric Food Chem 43(6):1493-1500.

Luning PA, de Rijk T, Wichers HJ, Roozen JP. 1994. Gas chromatography, mass spectrometry, and sniffing port analyses of volatile compounds of fresh bell peppers (Capsicum annuиm) at different ripening stages. J Agric Food Chem 42(4):977-983. 
Luning PA, Ebbenhorst-Seller T, de Rijk T, Roozen JP. 1995b. Effect of hot-air drying on flavor compounds of bell peppers (Capsicum annuum). J Sci Food Agric 68(3):355-365.

Maarse H. 1991. Volatile compounds in foods and beverages. New York: Marcel Dekker Inc. $767 \mathrm{p}$.

Mateo J, Aguirrezábal M, Domínguez C, Zumalacárregui JM. 1997. Volatile compounds in Spanish paprika. J Food Compos Anal 10(3):225-232.

Minguez-Mosquera MI, Jaren-Galan M, Garrido-Fernandez J. 1993. Lipoxygenase activity during pepper ripening and processing of paprika. Phytochemistry 32(5):1103-1108.

Naef R, Velluz A, Jaquier A. 2008. New volatile sulfur-containing constituents in a simultaneous distillation-extraction extract of red bell peppers (Capsicum anпиит). J Agric Food Chem 56(2):517-527.

Nielsen GS, Larsen LM, Poll L. 2003. Formation of aroma compounds and lipoxygenase (EC 1.13.11.12) activity in unblanched leek (Allium ampeloprasum var. Bulga) slices during long-term frozen storage. J Agric Food Chem 51(7):1970-1976.

Nielsen GS, Larsen LM, Poll L. 2004a. Formation of aroma compounds during long-term frozen storage of unblanched leek (Allium ampeloprasum var. Bulga) as affected by packaging atmosphere and slice thickness. J Agric Food Chem 52(5):1234-1240.

Nielsen GS, Larsen LM, Poll L. 2004b. Impact of blanching and packaging atmosphere on the formation of aroma compounds during long-term frozen storage of leek (Allium ampeloprasum var. Bulga) slices. J Agric Food Chem 52(15):4844-4852.

Nielsen GS, Poll L. 2004. Determination of odor active aroma compounds in freshly cut leek (Allium ampeloprasum var. Bulga) and in long-term stored frozen unblanched and blanched leek slices by gas chromatography olfactometry analysis. J Agric Food Chem 52(6):1642-1646.

Oruña-Concha M, Lopez-Hernandez J, Simal-Lozano J, Simal-Gandara J, GonzalezCastro M, Garcia C. 1998. Determination of volatile components in fresh, frozen, and freeze-dried Padron-type peppers by gas chromatography mass spectrometry using dynamic headspace sampling and microwave desorption. J Chromatogr Sci 36(12):583-588.

Pino J, González M, Ceballos L, Centurión-Yah AR, Trujillo-Aguirre J, LatournerieMoreno L, Sauri-Duch E. 2007. Characterization of total capsaicinoids, colour and 
volatile compounds of Habanero chilli pepper (Capsicum chinense Jack.) cultivars grown in Yucatan. Food Chem 104(4):1682-1686.

Rajput JC, Parulekar YR. 1998. Capsicum. In: D. K. Salunkhe, S. S. Kadam, editors. Handbook of vegetable science and technology: production, composition, storage, and processing. New York: Marcel Dekker, Inc. p203-224.

Rotsatchakul P, Chaiseri S, Cadwallader K. 2008. Identification of characteristic aroma components of Thai fried chili paste. J Agric Food Chem 56(2):528-536.

Scherb J, Kreissl J, Haupt S, Schieberle P. 2009. Quantitation of S-Methylmethionine in raw vegetables and green malt by a stable isotope dilution assay using LC-MS/MS: comparison with dimethyl sulfide formation after heat treatment. J Agric Food Chem 57(19):9091-9096.

Sousa ET, Rodrigues F dM, Martins CC, de Oliveira FS, Pereira PA, de Andrade JB. 2006. Multivariate optimization and HS-SPME/GC-MS analysis of VOCs in red, yellow and purple varieties of Capsicum chinense sp. peppers. Microchem J 82(2):142-149.

Spanel P, Ji Y, Smith D. 1997. SIFT studies of the reactions of $\mathrm{H}_{3} \mathrm{O}^{+}, \mathrm{NO}^{+}$, and $\mathrm{O}_{2}{ }^{+}$with a series of aldehydes and ketones. Int J Mass Spectrom Ion Proc 165/166:25-37.

Spanel P, Smith D. 1997. SIFT studies of the reactions of $\mathrm{H}_{3} \mathrm{O}^{+}, \mathrm{NO}^{+}$, and $\mathrm{O}_{2}{ }^{+}$with a series of alcohols. Int J Mass Spectrom Ion Proc 167/168:375-388.

Spanel P, Smith D. 1998. SIFT studies of the reactions of $\mathrm{H}_{3} \mathrm{O}^{+}, \mathrm{NO}^{+}$, and $\mathrm{O}_{2}{ }^{+}$with a series of volatile carboxylic acids and esters. Int J Mass Spectrom Ion Proc 172:137-147.

Spanel P, Smith D. 1999. Selected ion flow tube - mass spectrometry: detection and realtime monitoring of flavours released by food products. Rapid Commun Mass Spectrom 13(7):585-596.

Spanel P, Van Doren J, Smith D. 2002. A selected ion flow tube study of the reaction of $\mathrm{H}_{3} \mathrm{O}^{+}, \mathrm{NO}^{+}$, and $\mathrm{O}_{2}{ }^{+}$with saturated and unsaturated aldehydes and subsequent hydration of the product ions. Int J Mass Spectrom 213:163-176.

Syft Technologies. 2009. Kinetics library database. Syft Technologies Inc., Christchurch, New Zealand. www.syft.com.

Syft Technologies. 2010. The SIFT-MS technique. Syft Technologies Inc., Christchurch, New Zealand. As cited in May 2010. www.syft.com/technology/ 
Teranishi R, Wick EL, Hornstein I. 1999. Flavor chemistry: thirty years of progress, an overview. In: Teranishi R, Wick EL, Hornstein I, editors. Flavor chemistry: thirty years of progress. New York: Springer. p 1-8.

USDA. 2010. National Nutrient Database for Standard Reference. Agricultural Research Service. http://www.nal.usda.gov/fnic/foodcomp/search/

van Ruth S, Boscaini E, Mayr D, Pugh J, Posthumus M. 2003. Evaluation of three gas chromatography and two direct mass spectrometry techniques for aroma analysis of dried red bell peppers. Int J Mass Spectrom 223-224:55-65.

Vazquez-Landaverde PA, Torres JA, Qian MC. 2006. Quantification of trace volatile sulfur compounds in milk by solid-phase microextraction and gas chromatographypulsed flame photometric detection. J Dairy Sci 89(8):2919-2927.

Vazquez-Landaverde PA, Velazquez G, Torres JA, Qian MC. 2005. Quantitative determination of thermally derived off-flavor compounds in milk using solid-phase microextraction and gas chromatography. J Dairy Sci 88(11):3764-3772.

Wang T, Spanel P, Smith D. 2003. Selected ion flow tube, SIFT, studies of the reactions of $\mathrm{H}_{3} \mathrm{O}^{+}, \mathrm{NO}^{+}$, and $\mathrm{O}_{2}{ }^{+}$with eleven $\mathrm{C}_{10} \mathrm{H}_{16}$ monoterpenes. Int $\mathrm{J}$ Mass Spectrom 228(1):117-126.

Wu CM, Liou SE. 1986. Effect of tissue disruption on volatile constituents of bell peppers. J Agric Food Chem 34(4):770-772.

Wu CM, Liou SE, Wang MC. 1986. Changes in volatile constituents of bell peppers immediately and 30 minutes after stir frying. J Am Oil Chem Soc 63(9):1172-1175.

$\mathrm{Xu}$ Y, Barringer S. 2009. Effect of temperature on lipid-related volatile production in tomato puree. J Agric Food Chem 57(19):9108-9113.

$\mathrm{Xu}$ Y. Barringer S. 2010. Comparison of volatile release in tomatillo and different varieties of tomato during chewing. J Food Sci 75(4):352-358.

Yu MH, Salunkhe DK, Olson LE. 1968. Production of 3-methylbutanal from L-leucine by tomato extract. Plant Cell Physiol 9(4):633-638.

Zimmermann M, Schieberle P. 2000. Important odorants of sweet bell pepper powder (Capsicum anпиит cv. annuиm): differences between samples of Hungarian and Morrocan origin. Eur Food Res Technol 211(3):175-180. 